\title{
A Water Balance-Based, Spatiotemporal Evaluation of Terrestrial Evapotranspiration Products across the Contiguous United States $\mathscr{\mathscr { O }}$
}

\author{
ELIZABETH CARTER \\ Department of Biological and Environmental Engineering, Cornell University, Ithaca, New York \\ CHRISTOPHER HAIN \\ NASA Short-Term Prediction Research and Transition Center, Huntsville, Alabama \\ MARTHA ANDERSON \\ Hydrology and Remote Sensing Laboratory, Agricultural Research Service, USDA, Beltsville, Maryland \\ SCOTT STEINSCHNEIDER \\ Department of Biological and Environmental Engineering, Cornell University, Ithaca, New York
}

(Manuscript received 29 September 2017, in final form 14 March 2018)

\begin{abstract}
Accurate gridded estimates of evapotranspiration (ET) are essential to the analysis of terrestrial water budgets. In this study, ET estimates from three gridded energy balance-based products $\left(\mathrm{ET}_{\mathrm{EB}}\right)$ with independent model formations and data forcings are evaluated for their ability to capture long-term climatology and interannual variability in $\mathrm{ET}$ derived from a terrestrial water budget $\left(\mathrm{ET}_{\mathrm{WB}}\right)$ for 671 gauged basins across the contiguous United States. All three $\mathrm{ET}_{\mathrm{EB}}$ products have low spatial bias and accurately capture interannual variability of $\mathrm{ET}_{\mathrm{WB}}$ in the central United States, where $\mathrm{ET}_{\mathrm{EB}}$ and ancillary estimates of change in total surface water storage ( $\triangle$ TWS) from the GRACE satellite project appear to close terrestrial water budgets. In humid regions, $\mathrm{ET}_{\mathrm{EB}}$ products exhibit higher long-term bias, and the covariability of $\mathrm{ET}_{\mathrm{EB}}$ and $\mathrm{ET}_{\mathrm{WB}}$ decreases significantly. Several factors related to either failure of $\mathrm{ET}_{\mathrm{WB}}$, such as errors in $\Delta \mathrm{TWS}$ and precipitation, or failure of $\mathrm{ET}_{\mathrm{EB}}$, such as treatment of snowfall and horizontal heat advection, explain some of these discrepancies. These results mirror and build on conclusions from other studies: on interannual time scales, $\Delta$ TWS and error in precipitation estimates are nonnegligible uncertainties in ET estimates based on a terrestrial water budget, and this confounds their comparison to energy balance ET models. However, there is also evidence that in at least some regions, climate and landscape features may also influence the accuracy and long-term bias of ET estimates from energy balance models, and these potential errors should be considered when using these gridded products in hydrologic applications.
\end{abstract}

\section{Introduction}

After precipitation, evapotranspiration (ET) is the largest term in the terrestrial surface hydrologic budget (Haddeland et al. 2011). Virtually all water taken up by vegetation is evapotranspired, and as the largest anthropogenic use of surface and groundwater is the irrigation

\footnotetext{
Supplemental information related to this paper is available at the Journals Online website: https://doi.org/10.1175/JHM-D-170186.s1.
}

Corresponding author: Elizabeth Carter,ekc76@cornell.edu of cropland (Shiklomanov 2000; Döll et al. 2012), characterization of ET has important implications for managing human water consumption. The importance of ET for surface hydrologic budgets and agricultural water use motivates the need for continuous observation-based data sources that can characterize the spatial and temporal variability of ET at a level of detail that can help resolve key aspects of the terrestrial hydrologic cycle.

Surface energy budget-based models of ET have substantially enhanced the availability of spatially and temporally continuous ET estimates. Remotely sensed data have also been integrated into surface energy models (Kalma et al. 2008; Li et al. 2009; Glenn et al. 2011), including land 
surface models (LSMs; Anderson et al. 2015), to further increase the accuracy of energy budget-based ET estimates. Several methods for integrating remotely sensed observations into energy budget-based ET estimates are available, ranging from using remotely sensed data to increase resolution of vegetation parameters in surface energy models (Mu et al. 2011) to utilization of direct measurements of surface energy fluxes (Anderson et al. 2011).

Regardless of whether remotely sensed data are used, most gridded ET products derived from surface energy budget models (hereafter referred to as $\mathrm{ET}_{\mathrm{EB}}$ products) still require ancillary data on surface meteorological conditions, including but not limited to incident and reflected shortwave radiation, near-surface air temperature, vapor pressure, and wind speed (Kalma et al. 2008; Glenn et al. 2011). Because of differences in modeling approaches with regard to remotely sensed and meteorological data inputs, different $\mathrm{ET}_{\mathrm{EB}}$ products show unique patterns of space-time bias that are related to propagation of errors in forcing data (Ferguson et al. 2010; Vinukollu et al. 2011; Cai et al. 2014), conditions under which models are not well calibrated (Hain et al. 2015; Ferguson et al. 2010; French et al. 2005; Jiménez et al. 2011; Velpuri et al. 2013; Vinukollu et al. 2011), and climatic conditions where model assumptions fail (Anderson et al. 2012; Choi et al. 2009; Kustas et al. 2012).

Because of a lack of spatially continuous groundbased measurements of ET, $\mathrm{ET}_{\mathrm{EB}}$ products are difficult to validate at large spatial scales. One of the most common approaches to validate $\mathrm{ET}_{\mathrm{EB}}$ estimates is to evaluate their consistency with empirical estimates of ET based on a terrestrial water budget $\left(\mathrm{ET}_{\mathrm{WB}}\right)$, calculated for individual basins as

$$
\mathrm{ET}=P+G-Q-\Delta \mathrm{TWS},
$$

where $\mathrm{ET}(\mathrm{mm})$ is the mean basin ET, $P(\mathrm{~mm})$ is mean basin precipitation, $G(\mathrm{~mm})$ accounts for net interbasin groundwater flux, $Q(\mathrm{~mm})$ is basin runoff (normalized by drainage area), and $\Delta$ TWS ( $\mathrm{mm}$ ) is the change in basin total water storage between the current and previous time step (where total water storage is the total water stored in soil, surface water, groundwater, and vegetation). Interbasin groundwater flux is often assumed to be zero, especially in basins with limited anthropogenic withdrawals. In gauged basins, $Q$ is known with high accuracy. If estimates of basin $P$ are also available, then a water budget-based estimate of ET $\left(\mathrm{ET}_{\mathrm{WB}}\right)$ can be developed by assuming $\Delta \mathrm{TWS}$ is zero:

$$
\mathrm{ET}_{\mathrm{wB}}=P-Q .
$$

The approximation in Eq. (1.2) has conventionally been accepted if all terms are evaluated over a sufficiently long time period (annual or longer) to support the assumption that $\Delta \mathrm{TWS}=0$ (Twine et al. 2004).

There has been consensus that $\mathrm{ET}_{\mathrm{EB}}$ products fail to close long-term (Sheffield et al. 2009, Gao et al. 2010) and interannual (Zhang et al. 2012; Zeng et al. 2014; Velpuri et al. 2013; Han et al. 2015; Liu et al. 2016) terrestrial water budgets (i.e., $\mathrm{ET}_{\mathrm{EB}} \neq \mathrm{ET}_{\mathrm{WB}}$ ) in many regions in the contiguous United States (CONUS). Long-term nonclosure errors $\left(\overline{\varepsilon_{\mathrm{NC}}}=\overline{\mathrm{ET}_{\mathrm{EB}}}-\overline{\mathrm{ET}_{\mathrm{WB}}}\right.$, with overbars indicating multiyear averages) follow distinct spatial and climatic gradients, with arid regions exhibiting substantially lower long-term bias than humid regions (Sheffield et al. 2009; Gao et al. 2010). Similarly, most $\mathrm{ET}_{\mathrm{EB}}$ estimates appear better suited to estimate both multiyear trends and interannual variability in arid regions than in humid regions (Zhang et al. 2012; Zeng et al. 2014; Velpuri et al. 2013). As such, interannual nonclosure errors $\left(\varepsilon_{\mathrm{NC}}=\mathrm{ET}_{\mathrm{EB}}-\mathrm{ET}_{\mathrm{WB}}\right)$ exhibit similar regional patterns as long-term bias $\overline{\varepsilon_{\mathrm{NC}}}$.

The spatial characterization of long-term and interannual nonclosure errors provides insight into the accuracy of different $\mathrm{ET}_{\mathrm{EB}}$ products for different regions, providing valuable guidance for how such products can be used in different hydrologic applications. Unfortunately, these error estimates are confounded by potential error embedded in $\mathrm{ET}_{\mathrm{WB}}$. For instance, basin-average $P$ can exhibit longterm mean bias if estimated from a sparse gauging network, particularly in basins with stark topographic gradients (Prat and Nelson 2015). The interannual variance of basinaverage $P$ can also be biased if the variance of precipitation at the gauges used to develop the basin-averaged estimate is a poor representation of the true precipitation variability across the basin. Most likely, the variance of basin-average $P$ will be too high because variances of true areal averages should be lower than individual point estimates, but there are limited numbers of gauges available to estimate the areal averages. In addition to precipitation biases, recent studies that have incorporated changes to $\Delta$ TWS derived from the Gravity Recovery and Climate Experiment (GRACE) satellites indicate that interannual variability in $\triangle$ TWS may be an important component of the annual terrestrial water budget in many regions (Rodell and Famiglietti 2001; Rodell et al. 2004; Sahoo et al. 2011; Zeng et al. 2012; Han et al. 2015). Therefore, nonclosure errors between $\mathrm{ET}_{\mathrm{WB}}$ and $\mathrm{ET}_{\mathrm{EB}}$ are difficult to disentangle from uncertainty in basin $P$ and $\Delta$ TWS. There have been attempts to disentangle these terms using sensitivity analyses to elucidate regions where $\varepsilon_{\mathrm{NC}}$ is significantly influenced by precipitation uncertainty (Ferguson et al. 2010; Sheffield et al. 2009; Gao et al. 2010; Hain et al. 2015), or GRACE Tellus-based measures of $\Delta$ TWS (Sheffield et al. 2009; Gao et al. 2010), with results generally showing that precipitation uncertainty is an important component of $\varepsilon_{\mathrm{NC}}$. 
A key question underscoring these efforts is whether nonclosure errors are caused by bias in the mean or variance of components used to estimate $\mathrm{ET}_{\mathrm{WB}}$ (e.g., $P$, $\Delta$ TWS), or if the model formulations that underscore different $\mathrm{ET}_{\mathrm{EB}}$ products fail to capture fundamental processes that drive ET variability. In this study, we seek to advance the evaluation of $\mathrm{ET}_{\mathrm{EB}}$ across the CONUS, building on recent work exploring the accuracy of $\mathrm{ET}_{\mathrm{EB}}$ estimates at different spatial and temporal scales (Zhang et al. 2012; Han et al. 2015). Han et al. (2015) explored evidence of hydrologic consistency between $\mathrm{ET}_{\mathrm{WB}}$ and two very different $\mathrm{ET}_{\mathrm{EB}}$ products: the Noah LSM (Chen et al. 1996) and the ALEXI model (Anderson et al. 1997). In that study, the authors hypothesized that interannual nonclosure errors in Noah ET estimates $\left(\mathrm{ET}_{\mathrm{EB}}^{\mathrm{NOAH}}\right)$ were not due to failure of the model as previously argued (Zhang et al. 2012), but rather were linked to errors in estimated values of $\mathrm{ET}_{\mathrm{WB}}$. They found a marked improvement in correlation between $\mathrm{ET}_{\mathrm{WB}}$ and $\mathrm{ET}_{\mathrm{EB}}^{\mathrm{NOAH}}$ over a 10-yr period in the Mississippi River basin, particularly in the Ohio and upper Mississippi subbasins, when they included GRACE Tellus $\Delta$ TWS in the $\mathrm{ET}_{\mathrm{WB}}$ approximation in Eq. (1.1) (assuming $G$ to equal zero). Further, they found that the interannual correlation between $\mathrm{ET}_{\mathrm{EB}}^{\mathrm{NOAH}}$ and ALEXI ET estimates $\left(\mathrm{ET}_{\mathrm{EB}}^{\mathrm{ALEXI}}\right)$ was high across 15 different basins in the central United States, although the magnitude of interannual variability of ET from both products was low compared to the interannual variability of $\mathrm{ET}_{\mathrm{WB}}$. They concluded that higher interannual variability in $\mathrm{ET}_{\mathrm{WB}}$ over $\mathrm{ET}_{\mathrm{EB}}^{\mathrm{NOAH}}$ and $\mathrm{ET}_{\mathrm{EB}}^{\mathrm{ALEXI}}$ is an artifact of erroneously excluding $\Delta$ TWS from the $\mathrm{ET}_{\mathrm{WB}}$ estimate. The results supported the argument that the Noah LSM could provide accurate estimates of interannual ET variability in humid basins, in contrast to the conclusions of Zhang et al. (2012).

The work in Han et al. (2015) showed the importance of possible errors in $\mathrm{ET}_{\mathrm{WB}}$ when assessing $\mathrm{ET}_{\mathrm{EB}}$ estimates. However, their analysis was limited to the Mississippi River basin and based on 10 years of data, which limits the conclusions that can be made for $\mathrm{ET}_{\mathrm{EB}}^{\mathrm{NOAH}}$ in humid basins across the CONUS. In addition, the study used consistency between $\mathrm{ET}_{\mathrm{EB}}^{\mathrm{NOAH}}$ and $\mathrm{ET}_{\mathrm{EB}}^{\mathrm{ALXI}}$ as evidence that $\mathrm{ET}_{\mathrm{EB}}^{\mathrm{NOAH}}$ estimates were correct, which ignores the possibility that both products could exhibit similar errors despite their different estimation approaches. We also note that comparisons between $\mathrm{ET}_{\mathrm{EB}}^{\mathrm{NOAH}}$ and spatially interpolated $\mathrm{ET}$ estimates from a network of eddy covariance towers (Jung et al. 2009) in the Ohio basin were poor (correlation coefficient of $\sim 0.4$; Han et al. 2015), somewhat countering the claim that discrepancies between $\mathrm{ET}_{\mathrm{EB}}^{\mathrm{NOAH}}$ and $\mathrm{ET}_{\mathrm{WB}}$ in the Ohio were due to errors in $\mathrm{ET}_{\mathrm{WB}}$. Finally, error in $P$ has been shown to be a potentially large source of uncertainty in $\mathrm{ET}_{\mathrm{WB}}$ as well as in LSM-based ET estimates
(Hain et al. 2015), yet annual $\mathrm{ET}_{\mathrm{EB}}^{\mathrm{NOAH}}$ was the only ET estimate compared directly to $\mathrm{ET}_{\mathrm{WB}}$. Since $\mathrm{ET}_{\mathrm{EB}}^{\mathrm{NOAH}}$ and ET $_{\text {WB }}$ used in that study had the same $P$ forcing [from National Land Data Assimilation System 2 (NLDAS-2)], basin-level correlation between these two ET estimates could have been influenced by correlated errors in $P$.

In this study, we revisit the results of Han et al. (2015) using an expanded analysis to address some of the limitations of the original analysis. Specifically, we consider the following additions:

1) In addition to using $\mathrm{ET}_{\mathrm{EB}}^{\mathrm{NOAH}}$ and $\mathrm{ET}_{\mathrm{EB}}^{\mathrm{ALEXI}}$, we include an ET product that uses a similar model formulation to Noah, but which uses different information on local moisture anomalies and real-time remotely sensed vegetation indices from the MODIS platform to force moisture based reductions in ET $\left(\mathrm{ET}_{\mathrm{EB}}^{\mathrm{MOD} 16}\right.$; $\mathrm{Mu}$ et al. 2011).

2) We compare all three $\mathrm{ET}$ products $\left(\mathrm{ET}_{\mathrm{EB}}^{\mathrm{NOAH}}, \mathrm{ET}_{\mathrm{EB}}^{\mathrm{MOD} 16}\right.$, $\mathrm{ET}_{\mathrm{EB}}^{\mathrm{ALEI}}$ ) directly to $\mathrm{ET}_{\mathrm{WB}}$, expanding the study area to include 671 basins with substantial coverage over the CONUS.

3) We examine both long-term bias between $\mathrm{ET}_{\mathrm{WB}}$ and $\mathrm{ET}_{\mathrm{EB}}$ and interannual anomalies between $\mathrm{ET}_{\mathrm{WB}}$ and $\mathrm{ET}_{\mathrm{EB}}$ after accounting for long-term bias. By contrasting $\mathrm{ET}_{\mathrm{EB}}$ performance across products, comparing long-term and interannual nonclosure errors between $\mathrm{ET}_{\mathrm{EB}}$ and $\mathrm{ET}_{\mathrm{WB}}$, and relating these nonclosure errors to watershed characteristics, we characterize regional variability in $\mathrm{ET}_{\mathrm{EB}}$ performance.

4) We integrate a new $\triangle$ TWS product derived from the GRACE satellite data (GRACE Mascon; Wiese 2015) to evaluate hydrologic consistency between $\mathrm{ET}_{\mathrm{EB}}$ and $\mathrm{ET}_{\mathrm{WB}}$ and to assess the ability to combine $\mathrm{ET}_{\mathrm{EB}}$ with both GRACE Tellus and Mascon $\Delta \mathrm{TWS}$ to describe the difference between precipitation and runoff across the CONUS. Regional variability in the importance of $\Delta$ TWS for annual water budgets across the CONUS is discussed.

5) To further diagnose the cause of nonclosure errors, we assess regional relationships between nonclosure errors and other atmospheric and meteorological proxies besides $\Delta$ TWS (e.g., precipitation, horizontal heat advection, snow cover) that could be a source of error in either $\mathrm{ET}_{\mathrm{EB}}$ or $\mathrm{ET}_{\mathrm{WB}}$ estimates.

\section{Methods}

\section{a. ET data overview}

\section{1) WATER BALANCE ET}

$\mathrm{ET}_{\mathrm{WB}}$ was calculated for the 671 watersheds included in the large-sample basin-scale hydrometerological dataset 
developed by Newman et al. (2015) from the HydroClimatic Data Network (HCDN) 1988 dataset [marked "HCDN 2009" in the Geospatial Attributes of Gages for Evaluating Streamflow, version II (GAGES-II), dataset; Falcone et al. 2010]. The selection of these small to midsized gauged watersheds (median area $336 \mathrm{~km}^{2}$ ) was based on criteria for minimal human disturbance (Falcone et al. 2010) and data quality (including basinlevel density of precipitation gauges) and continuity. As an additional screening, we validated that basins included in the database had minimal irrigation by calculating the percent irrigated area using the MODIS Irrigated Agriculture Dataset for the United States (MIrAD-US; Pervez and Brown 2010). The vast majority of basins had negligible irrigated area.

Annual water year (October-September) discharge for each gauge was calculated between 2003 and 2015 and converted to annual runoff $Q(\mathrm{~mm})$ by dividing by drainage area. Precipitation data were taken from the NLDAS-2 (Xia et al. 2012) primary forcing dataset. Basin-average $P$ was calculated for water years 2003-15 by averaging all NLDAS grid cells whose centers are located within the basin (Hijmans and van Etten 2014). For each basin for each year, annual $\mathrm{ET}_{\mathrm{WB}}$ was calculated using Eq. (1.2), as was the 13-yr mean $\left(\overline{\mathrm{ET}_{\mathrm{WB}}}\right)$. Basins with any $\mathrm{ET}_{\mathrm{WB}}$ values less than zero were eliminated from the analysis.

\section{2) ENERgy BALANCE-BASED ET PRODUCTS}

In addition to the water budget approach, ET can be characterized using a surface energy budget as follows:

$$
\mathrm{Rn}=H+\mathrm{LE}+G,
$$

where $\mathrm{Rn}$ (net radiation, generally expressed as $\mathrm{W} \mathrm{m}^{-2}$ ) is partitioned to sensible heat flux $H\left(\mathrm{~W} \mathrm{~m}^{-2}\right)$, latent heat flux (LE; $\left.\mathrm{W} \mathrm{m}^{-2}\right)$, and ground heat flux $G\left(\mathrm{~W} \mathrm{~m}^{-2}\right)$, with the partitioning between them dependent on surface and atmospheric characteristics and conditions. $\mathrm{ET}_{\mathrm{EB}}(\mathrm{mm})$ can then be derived from LE by dividing by the latent heat of vaporization of water.

When there is unlimited water available for evapotranspiration, the partitioning of Rn between $H, G$, and LE can be modeled using a variety of physically based or empirical methods, where $G$ is generally assumed to be constant (often zero) on a daily or greater time step, and the relative partitioning of energy to $H$ and LE is dependent on surface meteorological conditions, including air temperature, relative humidity, wind speed, and vegetation cover.

While numerous surface energy budget-based $\mathrm{ET}_{\mathrm{EB}}$ exist [see Kalma et al. (2008) for a review], for the purposes of this study, we consider two basic classes:
1) In Penman-Monteith-based ET (ET $\left.\mathrm{EB}_{\mathrm{EB}}^{\mathrm{NOAH}}, \mathrm{ET}_{\mathrm{EB}}^{\mathrm{MOD} 16}\right)$, potential evapotranspiration (PET) is calculated from daily surface meteorological variables (reanalysis data) using a modified Penman-Monteith equation, with spatially variable vegetation indices used to estimate surface emissivity and resistance. PET is scaled to ET using time-varying estimates of moisture availability.

(i) For $\mathrm{ET}_{\mathrm{EB}}^{\mathrm{NOAH}}$ (Chen et al. 1996), NLDAS-2 Noah LSM ET output is calculated by the National Centers for Environmental Prediction (NCEP) using North American Regional Reanalysis (NARR) surface meteorological data fields, with NARR downward shortwave radiation biascorrected to the University of Maryland Surface Radiation Budget (SRB; Pinker et al. 2003), which uses data from the GOES-8 satellite. Resistance terms are applied to Penman-based PET for four separate terrestrial surface types (canopy transpiration, canopy evaporation of intercepted precipitation, soil evaporation, and sublimation). Resistance terms are modified by the underlying soil moisture, which is forced by NLDAS- $2 P$ (Xia et al. 2012, 2015; Peters-Lidard et al. 2011).

(ii) $\mathrm{The}_{\mathrm{EB}}^{\mathrm{MOD} 16}$ product (Mu et al. 2011) developed by the University of Montana uses Global Modeling and Assimilation Office (GMAO) ModernEra Retrospective Analysis for Research and Applications (MERRA; Rienecker et al. 2011) data, in conjunction with 8-day data inputs from the MODIS platform of the AVHRR satellite (leaf area index, enhanced vegetation index, and albedo) to calculate PET. As vegetation growth is primarily limited by water availability, realtime updates of local vegetation conditions from MODIS data are used to capture water-limited ET (Cleugh et al. 2007). Mu et al. (2007) updated this algorithm to scale evaporation by relative humidity and scale transpiration by vapor pressure deficit, used as a proxy indicator of soil moisture limitations.

2) In remotely sensed thermal infrared $\mathrm{ET}\left(\mathrm{ET}_{\mathrm{EB}}^{\mathrm{ALEXI}}\right.$; Anderson et al. 1997, 2011), $H$ is calculated from a time-differential linear model of atmospheric boundary layer $(\mathrm{ABL})$ development, which is forced with two measurements of radiometric surface temperature taken in the morning from GOES satellites, an initial estimate of ABL height from early morning sounding data, and wind speed to give an estimate of instantaneous $H$ flux at $1.5 \mathrm{~h}$ prior to solar noon. Instantaneous LE is then calculated using Eq. (2.1) and is converted to daily cumulative LE using ancillary estimates of daily cumulative insolation 
assuming a diurnally constant value of LE/Sdn, where Sdn is instantaneous solar radiation.

\section{b. Long-term nonclosure error}

To examine long-term nonclosure errors, the period of record bias was calculated as

$$
\overline{\varepsilon_{\mathrm{NC}}}=\overline{\mathrm{ET}_{\mathrm{EB}}}-\overline{\mathrm{ET}_{\mathrm{WB}}},
$$

where the overbar indicates the 2003-15 mean, and $\mathrm{ET}_{\mathrm{EB}}$ is based on either Noah, MOD16, or ALEXI estimates. We first evaluate and compare the distribution and spatial patterns of $\overline{\varepsilon_{\mathrm{NC}}}$ across the three energy balance models.

We then calculate the rank correlation between $\overline{\varepsilon_{\mathrm{NC}}}$ and a variety of watershed characteristics to determine the potential drivers of long-term bias. The majority of these watershed characteristics were extracted from the GAGES-II database (Falcone et al. 2010), with several exceptions. For example, percent (\%) irrigated area in each basin, a potential source of anthropogenic decoupling of true ET from $\mathrm{ET}_{\mathrm{WB}}$, was taken as the basin mean value for the MIrAD-US dataset (Pervez and Brown 2010). Mean horizontal heat advection $\overline{H_{\text {HORIZ }}}$ (a possible error source in $\mathrm{ET}_{\mathrm{EB}}$ ) was calculated as the basin mean of the square root of the sum of squared northward and eastward components of vertically integrated sensible heat flux for June-August (JJA) for the years 2003-15 from the ERA-Interim reanalysis product (Dee et al. 2011). For potential long-term water balance errors, mean $\Delta$ TWS for each basin was calculated using the method in Landerer and Swenson (2012) from 2003 to 2015 for the GRACE Tellus (Swenson 2012) and the newer GRACE Mascon (Save et al. 2016) data products (see supplemental text 1 in the online supplemental material for more detail). Since both $\mathrm{ET}_{\mathrm{EB}}^{\mathrm{MOD} 16}$ and $\mathrm{ET}_{\mathrm{EB}}^{\mathrm{ALEXI}}$ depend on remotely sensed data that may not be available on certain days (e.g., because of cloud cover), estimates depend on gap-filling procedures that could degrade their accuracy. Therefore, we used the average percent of pixel days with missing values [not available (NA)] per basin per year (mean \%NA pixel days) from the direct retrievals from GOES thermal imagery in the ALEXI product as a proxy for obstructive cloud cover.

Finally, to ensure that the results are not sensitive to the NLDAS-2 precipitation product used in the calculation of $\overline{\mathrm{ET}_{\mathrm{WB}}}$, we reevaluate the distribution of $\overline{\varepsilon_{\mathrm{NC}}}$ with $\overline{\mathrm{ET}_{\mathrm{WB}}}$ calculated from several different precipitation datasets (see supplemental text 2).

\section{c. Interannual nonclosure error}

Interannual nonclosure errors can arise from a variety of error sources in $\mathrm{ET}_{\mathrm{EB}}$ or $\mathrm{ET}_{\mathrm{WB}}$. In the case that these errors are caused by bias in the mean or variance of $\mathrm{ET}_{\mathrm{EB}}$ or $\mathrm{ET}_{\mathrm{WB}}$, it may still be possible to show hydrologic consistency in the direction of interannual change between $\mathrm{ET}_{\mathrm{EB}}$ and $\mathrm{ET}_{\mathrm{WB}}$ if the data are first mean adjusted and scaled. Therefore, we center both variables to remove long-term mean biases (with the prime indicating annual departure from the mean, $\mathrm{ET}^{\prime}=\mathrm{ET}-\overline{\mathrm{ET}}$ ) and also produce a scaled version of these data by dividing by the standard deviation (sd) [denoted $\left.\mathrm{sET}^{\prime}=(\mathrm{ET}-\overline{\mathrm{ET}}) / \mathrm{sd}(\mathrm{ET})\right]$. We then use geographically weighted regression (GWR) to explore how the relationship between $\mathrm{ET}_{\mathrm{WB}}$ and $\mathrm{ET}_{\mathrm{EB}}$ varies across space. GWR is a localized regression method that uses a kernel function and spatial bandwidth to pool data at nearby sites in the estimation of a regression linking response and predictor variables (Brunsdon et al. 1998). The resulting regression exhibits smooth variations in the coefficient estimates at different sites across space. GWR provides a compromise between calculating a single regression coefficient on the global dataset, which would eliminate spatial variability in the process, or calculating individual regression estimates for each point in the study area, which could result in unstable coefficient estimates with high standard errors due to low sample size. In this analysis, GWR models were built to explore the spatial variability in how well $\mathrm{ET}_{\mathrm{EB}}^{\prime}$ tracks interannual variability in $\mathrm{ET}_{\mathrm{WB}}^{\prime}$.

For each $\mathrm{ET}_{\mathrm{EB}}$ product, two GWR models were built:

$$
\begin{aligned}
\mathrm{sET}_{\mathrm{EB}^{i, t}}^{\prime} & =\beta_{i} \mathrm{sET}_{\mathrm{WB}^{i, t}}^{\prime}+\varepsilon_{i, t} \\
\mathrm{ET}_{\mathrm{EB}^{i, t}}^{\prime} & =\beta_{i} \mathrm{ET}_{\mathrm{WB}^{i, t}}^{\prime}+\varepsilon_{i, t},
\end{aligned}
$$

where $t$ indicates the year, and $i$ indicates the $i$ th basin. Parameter $\beta_{i}$ is allowed to smoothly vary across the CONUS by pooling nearby basins using a Gaussian kernel function with optimal bandwidth selected via cross validation (Bivand and $\mathrm{Yu}$ 2017). The first model [Eq. (2.3)] explores whether $\mathrm{sET}_{\mathrm{EB}}^{\prime}$ exhibits hydrologic consistency with $\mathrm{sET}_{\mathrm{WB}}^{\prime}$ after accounting for the potential of both mean and variance biases in all water and energy balance terms. The second model [Eq. (2.4)] explores the ability of $\mathrm{ET}_{\mathrm{EB}}^{\prime}$ to close interannual terrestrial water budgets in an absolute sense (less any mean biases in either $\mathrm{ET}_{\mathrm{EB}}$ or $\left.\mathrm{ET}_{\mathrm{WB}}\right)$. In particular, $\beta_{i}$ from Eq. (2.4) not only reflects the strength of the relationship between $\mathrm{ET}_{\mathrm{EB}}^{\prime}$ and $\mathrm{ET}_{\mathrm{WB}}^{\prime}$, but also the difference in magnitude of interannual fluctuations between energy balance and water balance ET (i.e., variance bias).

To better understand the distribution of errors exhibited by the GWR, we also examine the distribution 


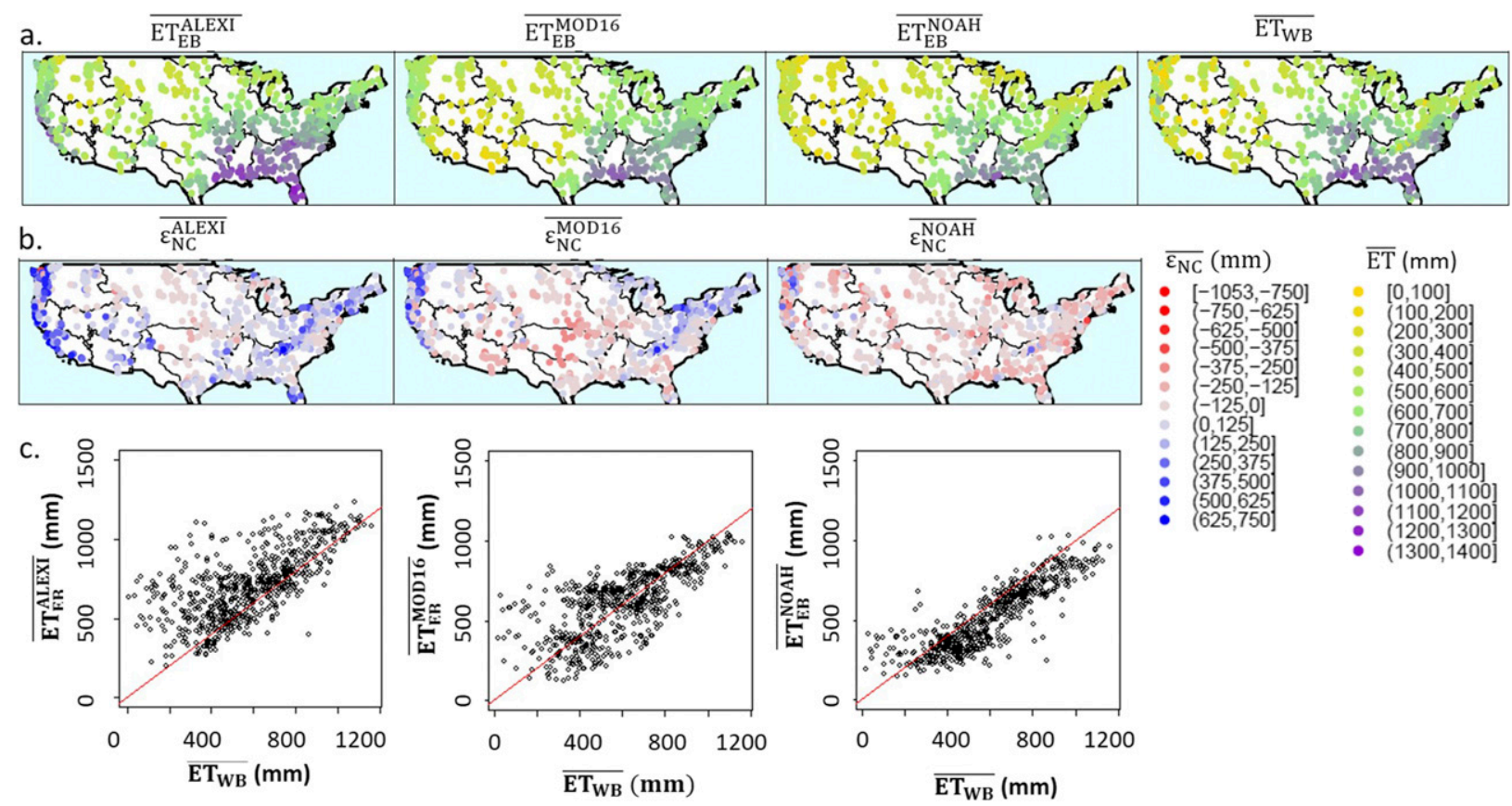

FIG. 1. (a) Spatial distribution of long-term mean annual ET from terrestrial water balance and energy balance models (color scale; $\mathrm{mm} \mathrm{yr}^{-1}$ ). Each point represents a streamflow gauging station. (b) Parameters $\overline{\varepsilon_{\mathrm{NC}}^{\mathrm{NOH}}}, \overline{\varepsilon_{\mathrm{NC}}^{\mathrm{MO} 16}}$, and $\overline{\varepsilon_{\mathrm{NC}}^{\mathrm{ALXI}}}\left(\mathrm{mm} \mathrm{yr}^{-1}\right)$, where positive $\overline{\varepsilon_{\mathrm{NC}}}$ (blue) indicates that $\overline{\mathrm{ET}_{\mathrm{EB}}}$ overpredicts relative to $\overline{\mathrm{ET}_{\mathrm{WB}}}$. (c) Scatterplot of $\overline{\mathrm{ET}_{\mathrm{EB}}}$ vs $\overline{\mathrm{ET}_{\mathrm{WB}}}$ with 1-to-1 line shown. Regular and square brackets represent inclusive and exclusive bounds of the interval, respectively.

of scaled, interannual nonclosure errors, calculated as the difference between the scaled, annual anomalies:

$$
{ }_{s} \varepsilon_{\mathrm{NC}}=\mathrm{sET}_{\mathrm{EB}}^{\prime}-\mathrm{sET}_{\mathrm{WB}}^{\prime} .
$$

For a particular region, any clustering in ${ }_{s} \varepsilon_{\mathrm{NC}}$ in certain years and not others would suggest that characteristics of specific climate events contribute substantially to discrepancies between $\mathrm{sET}_{\mathrm{EB}}^{\prime}$ and $\mathrm{sET}_{\mathrm{WB}}^{\prime}$. These discrepancies could arise from errors in both energy and water balancebased models. Likely sources of error in annual estimates of $\mathrm{ET}_{\mathrm{WB}}$ include errors in estimates of basin $P$ or violations in the assumption that changes in basin surface water storage ( $\Delta$ TWS $)$ are negligible on an annual time step. Energy balance models were not originally designed to operate at the continental scale, where horizontal fluxes of energy can lead to violations of the assumption of daily local conservation of energy (Trenberth et al. 2009). In addition, these models have parameterizations of sublimation that have been previously questioned (Wang et al. 2015). Therefore, we explore clustering in ${ }_{s} \varepsilon_{\mathrm{NC}}$ by product and year, and then correlate ${ }_{s} \varepsilon_{\mathrm{NC}}$ to several variables on an annual scale, including basin-average $P, \Delta$ TWS for both GRACE Tellus $\left(\Delta \mathrm{TWS}_{T}\right)$ and GRACE Mason $\left(\Delta \mathrm{TWS}_{M}\right)$ data products, percent of precipitation as snow from the ERA-Interim monthly data, and annual JJA horizontally advected sensible heat flux $\left(H_{\text {HORIZ }}\right)$.

\section{Results}

\section{a. Long-term nonclosure error}

The mean annual estimates for all water and energy balance models $\left(\overline{\mathrm{ET}_{\mathrm{WB}}}, \overline{\mathrm{ET}_{\mathrm{EB}}^{\mathrm{ALEXI}}}, \overline{\mathrm{ET}_{\mathrm{EB}}^{\mathrm{NOAH}}}\right.$, and $\overline{\mathrm{ET}_{\mathrm{EB}}^{\mathrm{MOD16}}}$ ) show similar spatial patterns, with the highest and lowest mean annual ET estimates seen in the Southeast and Southwest and western continental interior, respectively (Fig. 1a). However, ET $_{\mathrm{EB}}$ models exhibit several areas of disagreement in estimates of long-term mean annual ET with respect to $\mathrm{ET}_{\mathrm{WB}}$, as well as with each other (Fig. 1b). For example, in basins to the west of the Rockies along the California coast, $\overline{\mathrm{ET}}_{\mathrm{EB}}^{\mathrm{ALEXI}}$ predicts higher $\mathrm{ET}$ values compared to $\overline{\mathrm{ET}_{\mathrm{EB}}^{\mathrm{MOD} 16}}$ and $\overline{\mathrm{ET}}_{\mathrm{EB}}^{\mathrm{NOAH}}$, which are similar to those seen in the $\mathrm{ET}_{\mathrm{WB}}$ model. Over the entire CONUS, $\overline{\mathrm{ET}}_{\mathrm{EB}}^{\mathrm{NOAH}}$ tends to predict lower annual ET compared to the other three models. Values of $\overline{\mathrm{ET}_{\mathrm{EB}}^{\mathrm{MOD} 16}}$ and $\overline{\mathrm{ET}_{\mathrm{EB}}^{\mathrm{ALEXI}}}$ tend to be higher than $\overline{\mathrm{ET}_{\mathrm{WB}}}$ in the Pacific Northwest and in basins along the Appalachian mountain chain, while $\mathrm{ET}_{\mathrm{EB}}^{\mathrm{ALEXI}}$ is higher than all other ET estimates along the Gulf Coast and through Florida, and $\overline{\mathrm{ET}}_{\mathrm{EB}}^{\mathrm{MOD} 16}$ is lower than all other models in the central United States. The range (maximum minus minimum) of ET estimates across the CONUS is smaller for $\overline{\mathrm{ET}_{\mathrm{EB}}^{\mathrm{MOD} 16}}(924 \mathrm{~mm})$ and $\overline{\mathrm{ET}_{\mathrm{EB}}^{\mathrm{NOAH}}}$ (881 $\mathrm{mm})$ compared to $\mathrm{ET}_{\mathrm{EB}}^{\mathrm{ALEXI}}(1060 \mathrm{~mm})$, which is

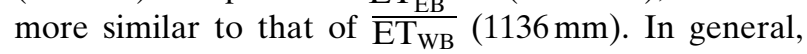


spatial consistency between the long-term means established by the four ET models appears to be lowest in the eastern third of the country and along the western coastline.

When analyzing Fig. 1, we note that errors in longterm basin-average $P$ (and thus $\overline{\mathrm{ET}_{\mathrm{WB}}}$ ) are expected for any particular basin, for example, due to gauge location within basin topography. It is less likely, however, that long-term error in orographically adjusted basinaveraged $P$ would be biased in the same direction across the 671 basins, although this possibility cannot be precluded because of documented undercatch of gauge precipitation linked to surface winds (Adam and Lettenmaier 2003; Yang et al. 2005) and/or potential systematic errors in data processing. However, the latter issue can be controlled for through the comparison of multiple products in the calculation of $\overline{\mathrm{ET}_{\mathrm{WB}}}$. Further, if the mean of the distribution of $\overline{\varepsilon_{\mathrm{NC}}}$ is significantly above zero for some $\mathrm{ET}_{\mathrm{EB}}$ products and below zero for others, we argue that one or more of these $\mathrm{ET}_{\mathrm{EB}}$ products are systematically biased compared to the true (and unknown) long-term ET.

In this context, we examine the distribution of $\overline{\varepsilon_{\mathrm{NC}}}$ for each of the three energy balance models in Fig. 1c. The mean of $\overline{\mathrm{ET}_{\mathrm{EB}}^{\mathrm{MOD} 16}}$ is relatively unbiased relative to $\overline{\mathrm{ET}_{\mathrm{WB}}}$, with a mean bias of about $4 \%$ above $\overline{\mathrm{ET}_{\mathrm{WB}}}$. The mean ALEXI-based ET estimates are approximately $120 \mathrm{~mm} \mathrm{yr}^{-1}$ higher than mean $\overline{\mathrm{ET}_{\mathrm{WB}}}$ on average, sug-

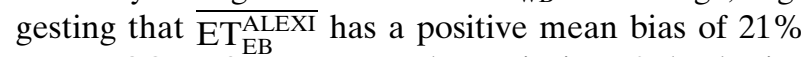
across CONUS. However, the majority of the basins with the highest values of $\overline{\varepsilon_{\mathrm{EB}}^{\mathrm{ALEI}}}$ are in mountainous regions (i.e., along the Cascades, Sierra Nevada, Rockies, and Appalachian Mountains), where topographic (slope and aspect) effects on the assumed net radiation [Rn in Eq. (2.1)] will impact the information content of remotely sensed data inputs. Removing basins with average slopes above $15 \%$ from the analysis (Fig. S1 in the supplemental material) reduces the positive mean bias of $\mathrm{ET}_{\mathrm{EB}}^{\mathrm{ALEXI}}$ to approximately $49 \mathrm{~mm} \mathrm{yr}^{-1}$ (or $9 \%$ ) above mean $\overline{\mathrm{ET}_{\mathrm{WB}}}$.

While the ALEXI and MOD16 products produce slightly higher long-term ET estimates on average than the water balance-based estimate, which is potentially consistent with undercatch in the NLDAS-2 precipitation product, the mean $\mathrm{ET}_{\mathrm{EB}}^{\mathrm{NOAH}}$ is about $80 \mathrm{~mm} \mathrm{yr}^{-1}$ lower than mean $\overline{\mathrm{ET}_{\mathrm{WB}}}$ on average (negative mean bias of about 13\%). Importantly, since both $\overline{\mathrm{ET}_{\mathrm{WB}}}$ and $\overline{\mathrm{ET}_{\mathrm{EB}}^{\mathrm{NOAH}}}$ are based on the same NLDAS-2 precipitation dataset, it is unlikely that this discrepancy is linked to systematic bias in the precipitation field. Further, the results are very similar if the scatterplots in Fig. 1c are replicated for $\overline{\mathrm{ET}_{\mathrm{WB}}}$ calculated with three additional gridded precipitation products (see Fig. S2 and supplemental text 2). A notable exception occurs when using the less accurate NLDAS-2 secondary precipitation forcing, which is based on the NARR reanalysis and is thus likely to be less accurate than gauged data. In this case, the Noah model exhibits the least longterm bias compared to $\mathrm{ET}_{\mathrm{WB}}$. Assuming that any systematic, long-term bias in $\overline{\mathrm{ET}_{\mathrm{WB}}}$ across the majority of basins would be a downward bias associated with undercatch, the results in Fig. 1 indicate that ALEXI and MOD16 models are more likely to be relatively unbiased with respect to the true, long-term ET across the CONUS, particularly in regions of mild terrain. Under this same assumption, Fig. 1 also suggests that there may be moderate negative biases in the mean long-term annual ET estimated by the Noah model.

The assessment above does not consider $\Delta$ TWS as a potential source of error in $\mathrm{ET}_{\mathrm{WB}}$, but this error should be minimized in the long-term average $\overline{\mathrm{ET}_{\mathrm{WB}}}$ because it is unlikely that there would be large changes in basin storage in basins with relatively little anthropogenic influences over a decadal period (i.e., $\Delta$ TWS should be near zero). To validate this assumption, 2003-15 $\Delta$ TWS was calculated using the GRACE Tellus $\left(\Delta \mathrm{TWS}_{T}\right)$ and GRACE Mascon $\left(\Delta \mathrm{TWS}_{M}\right.$ ) products (Fig. 2, left column). We found that for most regions in the CONUS, $\overline{\Delta T W S}$ was very close to zero, with an interquartile range across basins from -1.5 to $6.4 \mathrm{~mm}$ for $\overline{\Delta \mathrm{TWS}}_{T}$ and from 0.1 to $11.8 \mathrm{~mm}$ for $\overline{\Delta \mathrm{TWS}}_{M}$. It should be noted, however, that the standard deviations of $\overline{\Delta \text { TWS }}$ (Fig. 2, right column) suggest that interannual variability in $\Delta$ TWS may be important in some regions, and estimates are higher for $\overline{\Delta \mathrm{TWS}}_{M}$ than for $\overline{\Delta \mathrm{TWS}}_{T}$. Parameter $\overline{\Delta \mathrm{TWS}}_{M}$ indicates that the highly irrigated regions of southern California and near the Ogallala Aquifer are losing between approximately 20 and $30 \mathrm{~mm}$ of TWS per water year and that TWS in the Midwest may be increasing by about $10-20 \mathrm{~mm} \mathrm{yr}^{-1}$. However, large $\overline{\varepsilon_{\mathrm{NC}}}$ values for all of the energy balance products are found in regions where the absolute magnitudes of $\overline{\Delta T W S}$ are negligible, and even in regions with high-magnitude $\overline{\Delta \mathrm{TWS}}$, these values are still several times smaller than $\overline{\varepsilon_{\mathrm{NC}}}$ (Fig. S3). Further, changes in basin storage linked to irrigated water withdrawn from hydraulically disconnected groundwater sources (e.g., Ogallala Aquifer) should not substantially affect the ET in relatively natural basins without much irrigation. Therefore, it does not seem likely that $\overline{\Delta T W S}$ plays a large role in the long-term biases between $\mathrm{ET}_{\mathrm{WB}}$ and $\mathrm{ET}_{\mathrm{EB}}$ estimates.

To identify regional characteristics that could explain long-term nonclosure error $\overline{\varepsilon_{\mathrm{NC}}}$, we evaluated the Spearman correlation between $\overline{\varepsilon_{\mathrm{NC}}}$ and physical and meteorological characteristics associated with each watershed (Fig. 3). We note that absolute correlation coefficients above 0.08 are statistically significant $(\alpha=0.05)$ 
$\overline{\Delta T W S}(\mathrm{~mm})$

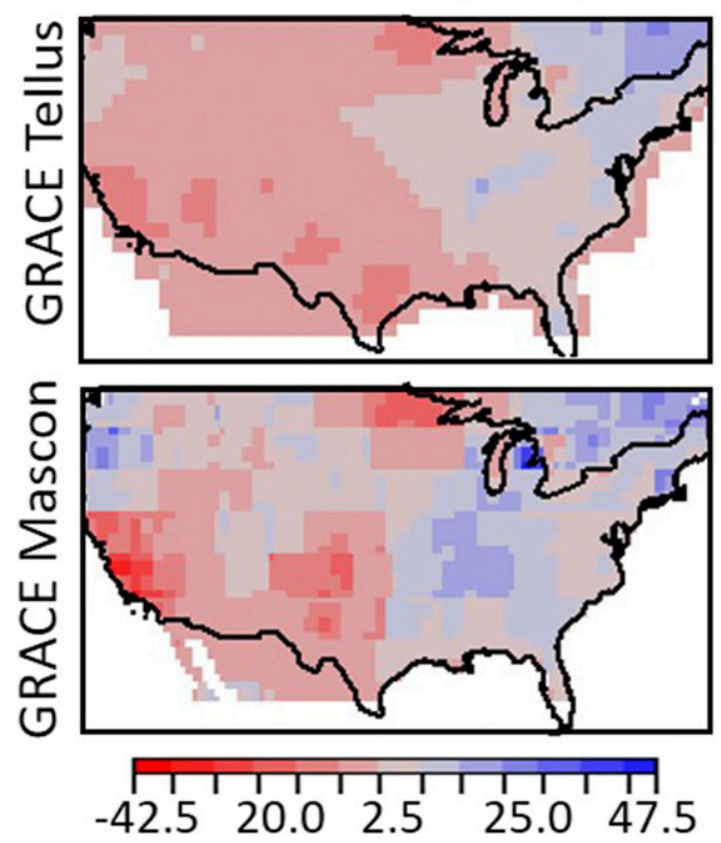

sd $\triangle$ TWS $(\mathrm{mm})$
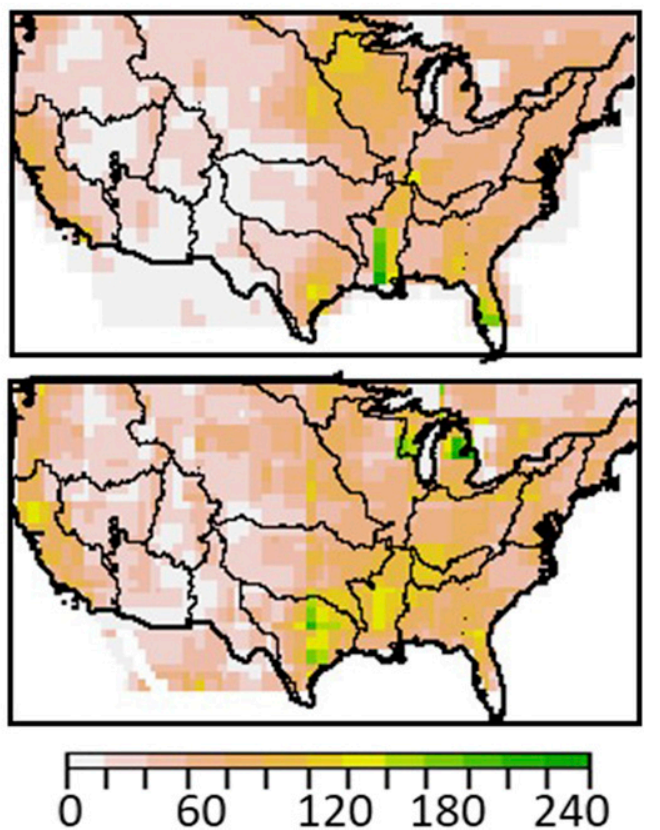

FIG. 2. (left) The 2003-15 mean $\Delta$ TWS (mm) calculated using GRACE (top) Tellus and (bottom) Mascon data products. Nonzero values indicate long-term change in September-October annual water storage, with positive (blue) values indicating net gain in $\Delta$ TWS and negative (red) values indicating net loss in $\Delta \mathrm{TWS}$. (right) As in the left panels, but for the standard deviation of 2003-15 $\Delta$ TWS (mm).

in a sample of 671 basins, but we focus on stronger relationships with absolute correlation coefficients above $0.4-0.6$ that indicate potentially more important relationships between watershed characteristics and $\overline{\varepsilon_{\mathrm{NC}}}$. Since many watershed characteristics are collinear, we interpret large correlations between $\overline{\varepsilon_{\mathrm{NC}}}$ and these characteristics as indicative of a strong association, but not necessarily a causal relationship.

One of the most notable results of the correlation analysis is that $\overline{\varepsilon_{\mathrm{NC}}^{\mathrm{ALXI}}}$ and $\overline{\varepsilon_{\mathrm{NC}}^{\mathrm{MOD} 16}}$ are strongly and positively correlated with mean annual $P$. In contrast, $\overline{\varepsilon_{\mathrm{NC}}^{\mathrm{NOH}}}$, which is forced with the same NLDAS-2 P used to calculate $\overline{\mathrm{ET}_{\mathrm{WB}}}$, shows no significant correlation with mean annual $P$. This result suggests that long-term bias in NLDAS-2 $P$ (and thus $\overline{\mathrm{ET}_{\mathrm{WB}}}$ ) for each basin may be a leading driver of long-term nonclosure error for the ALEXI and MOD16 models, but not for the Noah model because it is based on the same precipitation dataset. This conclusion is consistent with the smaller variance in the scatter of Fig. 1c for the Noah model compared to the ALEXI and MOD16 models.

Another notable result is that both $\overline{\varepsilon_{\mathrm{NC}}^{\mathrm{ALXI}}}$ and $\overline{\varepsilon_{\mathrm{NC}}^{\mathrm{MOD} 16}}$ show significant positive correlation with increasing mean percent slope (\%SLOPE) in the basin, a result that may indicate degradation of remotely sensed information in basins with complex terrain (also see Fig. S1). Alternatively, correlation between $\overline{\varepsilon_{\mathrm{NC}}^{\mathrm{ALEI}}}$ and $\overline{\varepsilon_{\mathrm{NC}}^{\mathrm{MOD} 16}}$ and \%SLOPE may be further evidence that NLDAS- $2 P$, and therefore $\overline{\mathrm{ET}_{\mathrm{WB}}}$, are negatively biased in regions with complex terrain. Though cloud cover has been associated with degraded performance of $\mathrm{ET}_{\mathrm{EB}}^{\mathrm{ALEXI}}$ at shorter time scales, the mean \%NA pixel days over

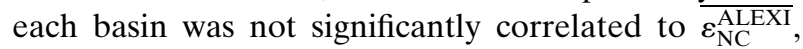
suggesting that cloudiness does not contribute to longterm model bias. However, $\overline{\varepsilon_{\mathrm{NC}}^{\mathrm{MOD} 16}}$ was significantly and negatively correlated to mean \%NA pixel days, suggesting that $\overline{\mathrm{ET}_{\mathrm{EB}}^{\mathrm{MOD} 16}}$ may be more likely to underestimate ET in cloudier basins. This discrepancy may be explained by the different ways that the ALEXI and MOD16 models gap-fill remotely sensed data.

Many of the remaining correlation coefficients are small, suggesting these relationships have little biophysical importance, though some are interesting to observe in the context of contrasting model formulation. For example, mean JJA horizontal heat advection $\overline{H_{\text {HORIZ }}}$ showed significant correlation with $\overline{\varepsilon_{\mathrm{NC}}^{\mathrm{MOD} 16}}$, but not $\overline{\varepsilon_{\mathrm{NC}}^{\mathrm{ALEI}}}$. This is interesting, as an increase in $\overline{H_{\mathrm{HORIZ}}}$ (i.e., large-scale heat advection) would be associated with an increase in estimation of LE/ET in the MOD16 model, whereas increasing $\overline{H_{\mathrm{HORIZ}}}$ would be associated with a direct decrease in 


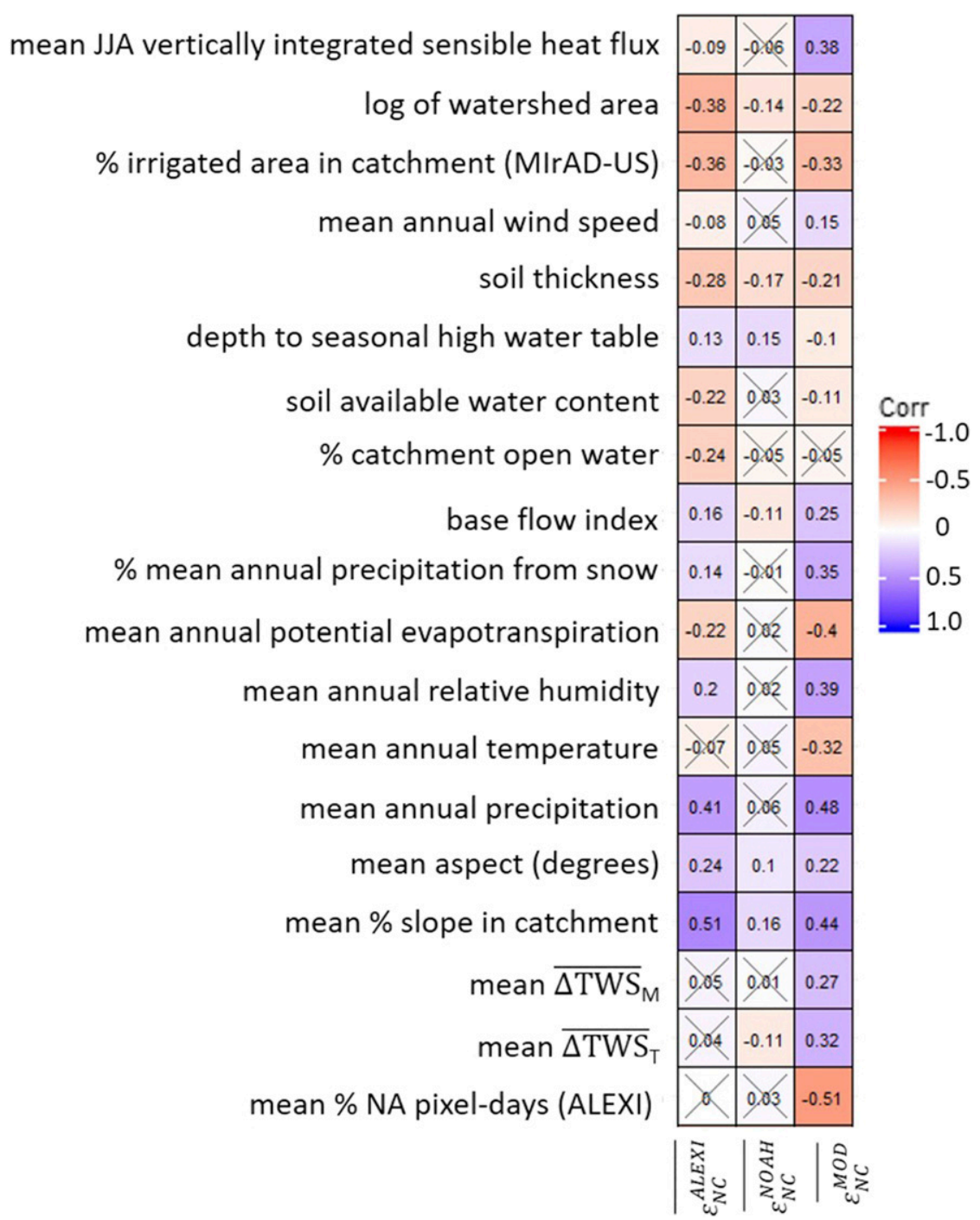

FIG. 3. Spearman's correlation coefficient between (left) $\overline{\varepsilon_{\mathrm{NC}}^{\mathrm{ALEI}}}$, (center) $\overline{\varepsilon_{\mathrm{NC}}^{\mathrm{NOH}}}$, and (right) $\overline{\varepsilon_{\mathrm{NC}}^{\mathrm{MOD} 16}}$ and watershed characteristics. The color scale represents the strength of negative (red) or positive (blue) correlation between the nonclosure error and watershed characteristic. Correlation coefficients that were not significant at $\alpha=0.05$ are indicated with an $\mathrm{X}$.

estimates of LE and ET (and an increase in estimates of $H$ ) in the ALEXI model. Also, weak correlations between $\overline{\varepsilon_{\mathrm{NC}}}$ and $\overline{\Delta T W S}_{M}$ and $\overline{\Delta T W S}_{T}$, particularly for $\overline{\varepsilon_{\mathrm{NC}}^{\mathrm{ALEX}}}$ and $\overline{\varepsilon_{\mathrm{NC}}^{\mathrm{NOH}}}$, further suggest that changes in basin storage are not driving discrepancies between water and energy budgetbased estimates of average annual ET (also see Fig. S3).

\section{b. Interannual nonclosure error}

We first evaluate the relationship between annual $\mathrm{ET}_{\mathrm{EB}}$ and $\mathrm{ET}_{\mathrm{WB}}$ estimates for water years $2003-15$ over the CONUS using GWRs. By contrasting the $\beta$ estimates for Noah, ALEXI, and MOD16 products and looking for regional coherence and discordance in these estimates, we hope to elucidate regions where hydrologic inconsistency is caused by annual errors in either $\mathrm{ET}_{\mathrm{EB}}$ or $\mathrm{ET}_{\mathrm{WB}}$. In particular, hydrologic consistency between $\mathrm{ET}_{\mathrm{WB}}$ and $\mathrm{ET}_{\mathrm{EB}}^{\mathrm{NOAH}}$ would be expected to be higher than hydrologic consistency between $\mathrm{ET}_{\mathrm{WB}}$ and both $\mathrm{ET}_{\mathrm{EB}}^{\mathrm{ALEI}}$ or $\mathrm{ET}_{\mathrm{EB}}^{\mathrm{MOD} 16}$ in basins where annual error in basin-level estimates from NLDAS-2 $P$ were of sufficient magnitude to lead to correlated errors in $\mathrm{ET}_{\mathrm{EB}}^{\mathrm{NOAH}}$ and $\mathrm{ET}_{\mathrm{WB}}$ estimates.

Figure 4 shows the spatial distribution of $\beta$ (Fig. 4a) and $R^{2}$ (Fig. 4b) for the GWR on scaled data [i.e., $\mathrm{sET}_{\mathrm{WB}}^{\prime}$ against $\mathrm{sET}_{\mathrm{EB}}^{\prime}$, Eq. (2.3)]. These spatial patterns are validated with location-specific regressions and Pearson correlation coefficients (see Fig. S4) to ensure that results are not an artifact of the spatial bandwidth chosen in the GWR models (Wheeler and Tiefelsdorf 2005). 
a.
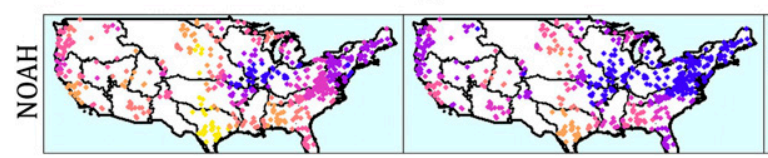

c.

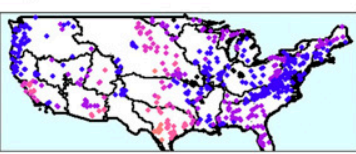

d.

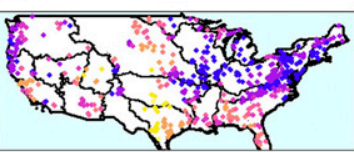

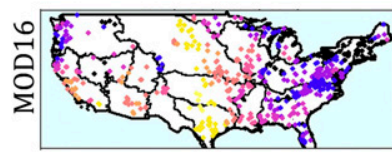
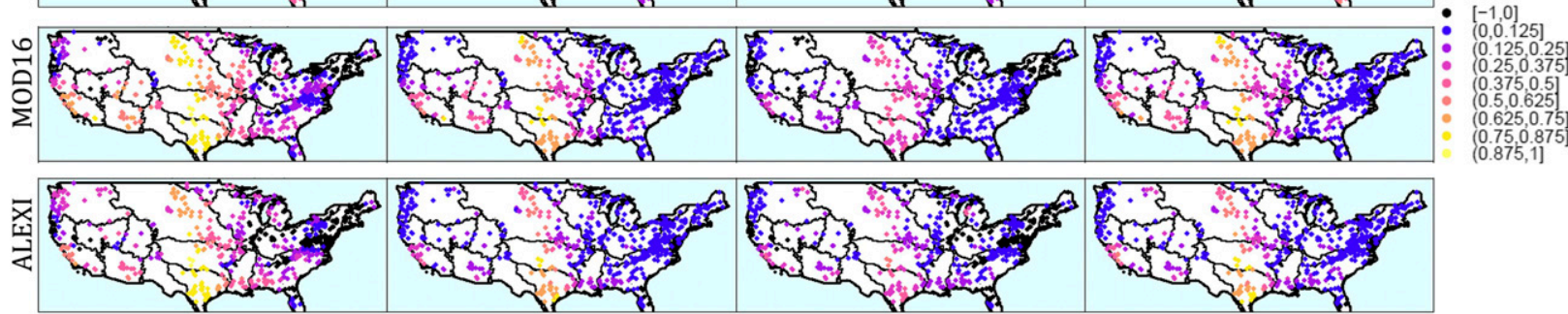

FIG. 4. (a) Geographically weighted $\beta$ estimates and (b) local $R^{2}$ for centered and scaled data [Eq. (2.3)], where each dot represents a basin. (c) Geographically weighted $\beta$ estimates and (d) local $R^{2}$ for unscaled data [Eq. (2.4)]. Outlines represent USGS HUC02 hydrologic regions across the CONUS.

Several patterns emerge when looking at the spatial distributions in Figs. 4a and 4b. First, the eastern portions of the Missouri, Arkansas-White-Red, and Texas-Gulf River basins have $\beta$ values that approach one, suggesting that for all three products, $\mathrm{ET}_{\mathrm{WB}}$ and $\mathrm{ET}_{\mathrm{EB}}$ track each other very closely. For all three models, $\beta$ values are also moderately high for basins in the lower Mississippi River, lower Colorado, and the southern part of the California basin. However, in all other regions of the CONUS, the variability in $\mathrm{ET}_{\mathrm{EB}}$ relative to $\mathrm{ET}_{\mathrm{WB}}$ diverges, and this divergence varies by energy balance model. For all $\mathrm{ET}_{\mathrm{EB}}$ estimates, $\beta$ values are lower in the east than in the continental interior and southwest coast. In addition, $\beta$ and $R^{2}$ values are higher for $\mathrm{ET}_{\mathrm{EB}}^{\mathrm{NOAH}}$ than for $\mathrm{ET}_{\mathrm{EB}}^{\mathrm{ALEXI}}$ and $\mathrm{ET}_{\mathrm{EB}}^{\mathrm{MOD} 16}$ in the Pacific Northwest and across most regions east of the Mississippi. For instance, where $\beta$ values are below 0.1 for $\mathrm{ET}_{\mathrm{EB}}^{\mathrm{MOD} 16}$ and $\mathrm{ET}_{\mathrm{EB}}^{\mathrm{ALEI}}$ for several basins in the New England and mid-Atlantic regions (suggesting no hydrologic consistency), they range between 0.1 and 0.4 for $\mathrm{ET}_{\mathrm{EB}}^{\mathrm{NOAH}}$. This suggests that in these regions, interannual errors in NLDAS-based basin $P$ likely play a role in the variability of nonclosure errors. Still, the $\beta\left(R^{2}\right)$ values for the Noah model are consistently below $0.5(0.25)$ for many eastern regions of the CONUS, indicating that there are other drivers of nonclosure error besides errors in $P$.

We also explore how the variance differs between $\mathrm{ET}_{\mathrm{EB}}$ and $\mathrm{ET}_{\mathrm{WB}}$. Pooling data from all gauges across the CONUS, the interannual variance of $\mathrm{ET}_{\mathrm{WB}}$ is (17167.8), which is much larger than that for MOD16 (1344.1), Noah (1890.9), and to a lesser extent, ALEXI (2751.6). The catchment level standard deviations of all ET estimates, as well as the ratios of variances between $\mathrm{ET}_{\mathrm{EB}}$ and $\mathrm{ET}_{\mathrm{WB}}$ for each basin, are shown in Fig. S5. This variance bias is also reflected in Figs. $4 \mathrm{c}$ and $4 d$, which show the $\beta$ and $R^{2}$ values for the GWR on unscaled data
[Eq. (2.4)]. These $\beta$ values are substantially lower than those for the scaled data (Fig. 4a), highlighting the large variance biases between $\mathrm{ET}_{\mathrm{WB}}$ and $\mathrm{ET}_{\mathrm{EB}}$. Figure 4 and Fig. S5 show that, in regions where hydrologic consistency between $\mathrm{sET}_{\mathrm{WB}}^{\prime}$ and $\mathrm{sET}_{\mathrm{EB}}^{\prime}$ is highest (see Fig. 4a), the variance of $\mathrm{ET}_{\mathrm{EB}}$ is about a quarter of that for $\mathrm{ET}_{\mathrm{WB}}$, regardless of energy balance model. In regions where hydrologic consistency is moderate or low, the variance of $\mathrm{ET}_{\mathrm{EB}}$ is almost two orders of magnitude less than that of $\mathrm{ET}_{\mathrm{WB}}$. This suggests that there is significant variance bias in either or both of the energy and water balancebased estimates. We speculate that for the water balance model, this may be related to inflated variance in basinaveraged estimates of annual precipitation.

Figure 4 and the comparison of $\beta$ and $R^{2}$ values between the energy balance models indicate that annual errors in basin $P$ have a large role in nonclosure errors, but other factors are also likely important. To explore this further, we first examine the distribution ${ }_{s} \varepsilon_{\mathrm{NC}}$ in individual years to determine if there are spatial patterns in the error term. Any clustering in ${ }_{s} \varepsilon_{\mathrm{NC}}$ in certain regions and years would suggest that characteristics of specific climate events contribute substantially to discrepancies between $\mathrm{sET}_{\mathrm{EB}}^{\prime}$ and $\mathrm{sET}_{\mathrm{WB}}^{\prime}$. Figure 5 shows the values of ${ }_{s} \varepsilon_{\mathrm{NC}}$ for two years with large-magnitude errors (2006 and 2012), with all years shown in Fig. S6. Clustering in ${ }_{s} \varepsilon_{\mathrm{NC}}$ is clearly apparent. For instance, in 2012, all three $\mathrm{sET}_{\mathrm{EB}}^{\prime}$ estimates were well above $\mathrm{sET}_{\mathrm{WB}}^{\prime}$ in the Northeast region, whereas in 2006 the opposite trend occurs. Further, in 2006, the errors are of much higher magnitude for MOD16 than the other products. Clustering of higher-magnitude annual ${ }_{s} \varepsilon_{\mathrm{NC}}$ appears to be strongest in regions where hydrologic consistency between $\mathrm{ET}_{\mathrm{EB}}$ and $\mathrm{ET}_{\mathrm{WB}}$ is lowest (Fig. 4).

To further diagnose this clustering and the cause of inconsistencies (i.e., low $\beta$ and $R^{2}$ values and low 


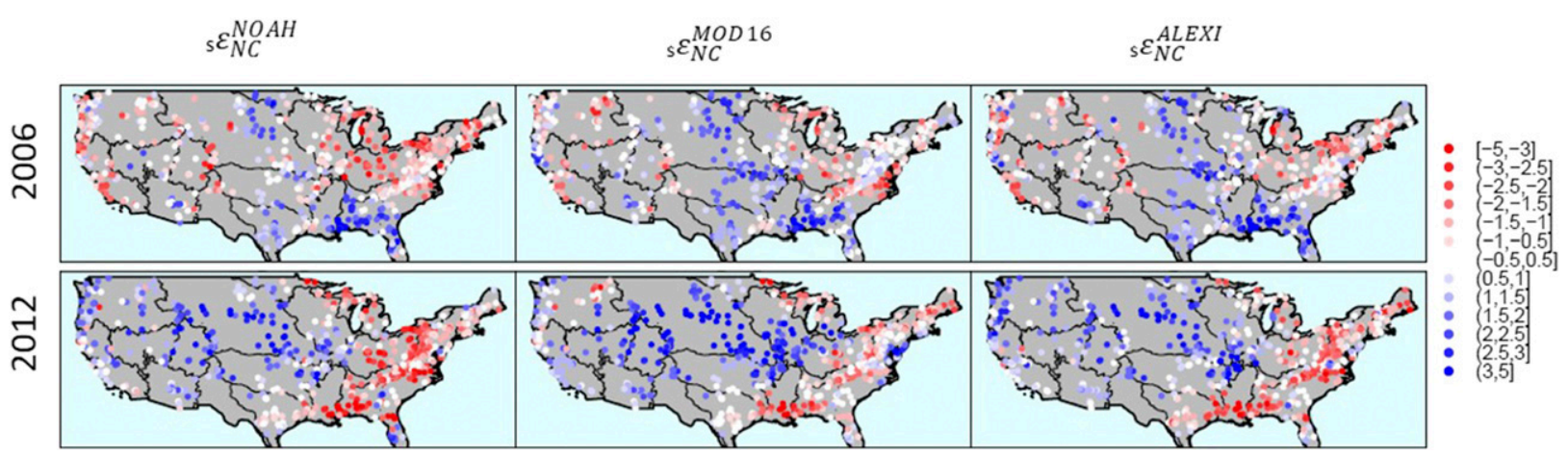

FIG. 5. The 2006 and 2012 spatial patterns in (left) ${ }_{s} \varepsilon_{\mathrm{NC}}^{\mathrm{NOH}}$, (center) ${ }_{s} \varepsilon_{\mathrm{NC}}^{\mathrm{MOD} 16}$, and (right) ${ }_{s} \varepsilon_{\mathrm{NC}}^{\mathrm{ALXI}}$.

variance ratios) revealed in the regressions above, scaled, nonclosure errors $\left({ }_{s} \varepsilon_{\mathrm{NC}}\right)$ are related to a series of atmospheric and meteorological proxies that could represent the cause of errors in $\mathrm{ET}_{\mathrm{WB}}$ or $\mathrm{ET}_{\mathrm{EB}}$ estimates. The first row of Fig. 6 shows the correlation between ${ }_{s} \varepsilon_{\mathrm{NC}}$ and basin $P$. Parameter ${ }_{s} \varepsilon_{\mathrm{NC}}^{\mathrm{ALEXI}}$ shows broad negative correlations with basin $P$ estimates across the CONUS, particularly in the Northeast, suggesting that scaled anomalies of $\mathrm{ET}_{\mathrm{EB}}^{\mathrm{ALEI}}$ are low relative to scaled anomalies in $\mathrm{ET}_{\mathrm{WB}}$ when $P$ is above average. For ${ }_{s} \varepsilon_{\mathrm{NC}}^{\mathrm{MOD} 16}$ and ${ }_{s} \varepsilon_{\mathrm{NC}}^{\mathrm{NOAH}}$, the pattern of correlation coefficients for $P$ is similar to that for ALEXI but somewhat muted, particularly along the Rocky Mountains. These results could be interpreted to suggest that when estimates of $P$ are either too high or too low, the error propagates into $\mathrm{ET}_{\mathrm{WB}}$ and contributes to nonclosure errors (i.e., we have high variance bias in $P$ ). Alternatively, it might suggest that errors in $\mathrm{ET}_{\mathrm{EB}}$ could be anticorrelated with $P$.

However, the similarity of the relationship between $P$ and both ${ }_{s} \varepsilon_{\mathrm{NC}}^{\mathrm{MOD} 16}$ and ${ }_{s} \varepsilon_{\mathrm{NC}}^{\mathrm{NOH}}$ is somewhat surprising, given similar formulations of the Noah and MOD16 products and that the Noah product is the only $\mathrm{ET}_{\mathrm{EB}}$ model based on the same $P$ data as the $\mathrm{ET}_{\mathrm{WB}}$ model. This may be partially explained by correlations between the precipitation products used by Noah (NLDAS-2) and MOD16 (GMAO). This may also be partially explained when examining the correlations between $\Delta$ TWS and ${ }_{s} \varepsilon_{\mathrm{NC}}$. Like Han et al. (2015), we examine how ${ }_{s} \varepsilon_{\mathrm{NC}}$ relates to $\Delta$ TWS, but we examine this relationship for both the Tellus and Mascon GRACE products (Fig. 6, rows 2 and 3) to evaluate whether recent advances in processing of GRACE data have improved $\Delta$ TWS estimates. The ${ }_{s} \varepsilon_{\mathrm{NC}}$ values for all three models show high negative correlation with both GRACE products in the Souris-Red-Rainy, Great Lakes, New England, and mid-Atlantic regions. Parameters $\varepsilon_{s} \varepsilon_{\mathrm{NC}}^{\mathrm{NOAH}}$ and $\varepsilon_{s} \varepsilon_{\mathrm{NC}}^{\mathrm{ALXI}}$ also show strong, negative correlations with $\Delta \mathrm{TWS}_{M}$ and $\Delta \mathrm{TWS}_{T}$ in the upper Mississippi basin, while ${ }_{s} \varepsilon_{\mathrm{NC}}^{\mathrm{MOD} 16}$ and ${ }_{s} \varepsilon_{\mathrm{NC}}^{\mathrm{ALEI}}$ show strong negative correlations with both GRACE products in the
Pacific Northwest. The results are very similar across both GRACE products, although some differences can be seen (e.g., for MOD16 in the Ohio River basin), and the relationships are slightly stronger with the newer Mascon data compared to the Tellus data (see Fig. S7), which exhibits slightly more interannual variability than Tellus (Figs. 2 and S7). We note these results were seen in spite of the fact that many basins used in this study were well below the minimum spatial resolution of the GRACE products. We also note that if $\Delta$ TWS is included directly in the $\mathrm{ET}_{\mathrm{WB}}$ estimates, the sign of ${ }_{s} \varepsilon_{\mathrm{NC}}$ generally does not change, and there are only modest impacts to the magnitude of nonclosure errors (Figs. S8, S9). These modest impacts may be caused by a variance bias in either $P$ or $\Delta$ TWS, motivating the use of the correlation analysis in Fig. 6 to control for these potential biases and maximize the potential signal between nonclosure errors and $\Delta \mathrm{TWS}$ (supplemental text 3).

Overall, the correlations between ${ }_{s} \varepsilon_{\mathrm{NC}}$ and $\Delta \mathrm{TWS}$ are strongest in many of the same basins with strong correlations between $P$ and ${ }_{s} \varepsilon_{\mathrm{NC}}$. These results indicate that the correlations between $P$ and ${ }_{s} \varepsilon_{\mathrm{NC}}$ may be the result of errors in $\mathrm{ET}_{\mathrm{WB}}$ linked to $\Delta \mathrm{TWS}$ that are strongest when conditions are wet. This makes it difficult to assess whether errors in $P$ or the omission of $\triangle$ TWS is driving the nonclosure error. Furthermore, both Noah and MOD16 scale ET by moisture availability, and so in theory, errors in this scaling process could lead to the correlations between ${ }_{s} \varepsilon_{\mathrm{NC}}, P$, and $\Delta$ TWS seen in Fig. 6. However, ALEXI does not scale ET based on moisture and still has similar correlations between ${ }_{s} \varepsilon_{\mathrm{NC}}, P$, and $\Delta$ TWS. Therefore, the strong relationships between ${ }_{s} \varepsilon_{\mathrm{NC}}$ and both $P$ and $\Delta$ TWS suggest that some combination of uncertainties linked to $\mathrm{ET}_{\mathrm{WB}}$ play a large role in nonclosure errors.

We are also interested in whether violations of assumptions in the energy balance models drive nonclosure errors, particularly as they relate to regional climate phenomena that could translate to regional clustering of ${ }_{s} \varepsilon_{\mathrm{NC}}$. We consider two such phenomena: $\% P$ from 

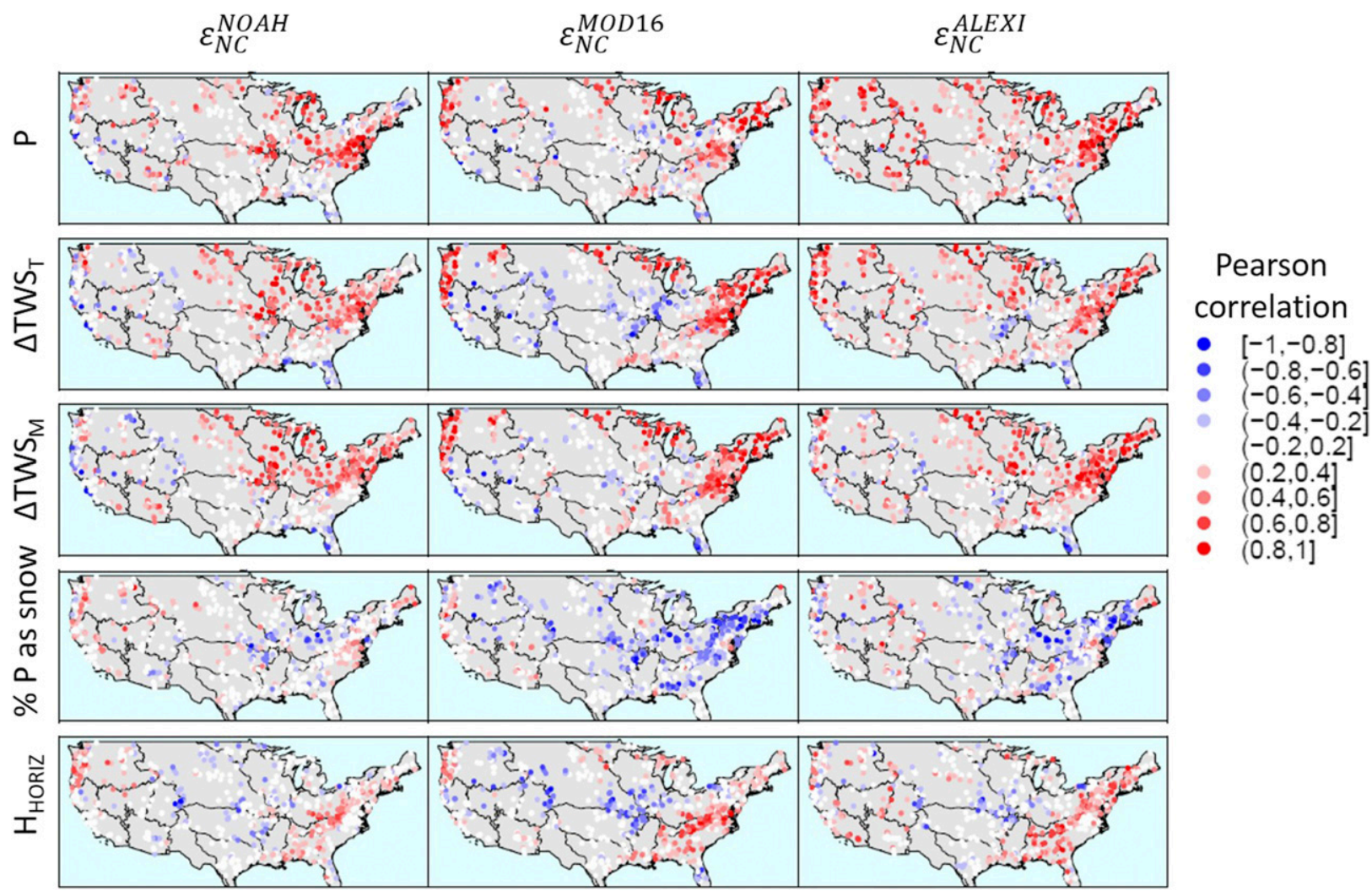

FIG. 6. Basin-specific correlations between (left) ${ }_{s} \varepsilon_{\mathrm{NC}}^{\mathrm{NOH}}$, (center) ${ }_{s} \varepsilon_{\mathrm{NC}}^{\mathrm{MOD} 16}$, and (right) ${ }_{s} \varepsilon_{\mathrm{NC}}^{\mathrm{ALXI}}$ and (top) annual $P$, (second row) annual $\Delta \mathrm{TWS}_{T}$, (third row) annual $\Delta \mathrm{TWS}_{M}$, (fourth row) $\% P$ as snow, and (bottom) JJA vertically integrated sensible heat flux $H_{\mathrm{HORIZ}}$.

snow (Fig. 6, row 4) and large-scale horizontal heat advection $H_{\mathrm{HORIZ}}$ (Fig. 6, row 5). Parameter ${ }_{s} \varepsilon_{\mathrm{NC}}$ shows positive correlations to $\% P$ as snow in the Ohio River and northern mid-Atlantic regions for all models, suggesting that in these areas, overestimation of $\mathrm{sET}_{\mathrm{EB}}^{\prime}$ relative to $\mathrm{sET}_{\mathrm{WB}}^{\prime}$ was higher in years when more $P$ came as snowfall. This relationship is strongest for MOD16, suggesting that wintertime ET (associated with sublimation) may be overestimated in this routine. It should be noted, however, that $P$ undercatch is accentuated during snowy conditions, which could further bias $\mathrm{ET}_{\mathrm{WB}}$ downward (Yang et al. 2005; Pan et al. 2003).

An interesting pattern also emerges when ${ }_{s} \varepsilon_{\mathrm{NC}}$ is compared to $H_{\mathrm{HORIZ}}$. Years when $H_{\mathrm{HORIZ}}$ is high seem to be associated with underestimation of all three $\mathrm{SET}_{\mathrm{EB}}^{\prime}$ relative to $\mathrm{sET}_{\mathrm{WB}}^{\prime}$ in the mid-Atlantic, southern Ohio, Tennessee, and South Atlantic Gulf regions. In contrast, large values of $H_{\mathrm{HORIZ}}$ appear to be associated with an overestimation of $\mathrm{sET}_{\mathrm{EB}}^{\mathrm{MOD} 16}$ relative to $\mathrm{SET}_{\mathrm{WB}}$ at the corner of the Missouri, upper Mississippi, Arkansas-White-Red, and lower Mississippi regions. Interestingly, in these same regions, MOD16 appears to differ most strongly from other ET products in general, though more research is needed to identify the reasons for this discrepancy. Overall, errors in $P$ and $\Delta$ TWS appear more related to nonclosure errors than $\% P$ as snow and $H_{\mathrm{HORIZ}}$ for most products and regions, although all variables appear important in at least some regions.

\section{Discussion and conclusions}

In this study, long-term average and interannual ET from three gridded energy balance products were evaluated against ET calculated from a simple terrestrial water budget in 671 basins across the CONUS for water years 2003-15. For long-term biases, $\overline{E T}_{\mathrm{EB}}^{\mathrm{ALEXI}}$ showed evidence of some overestimation of annual ET relative to $\overline{\mathrm{ET}_{\mathrm{WB}}}$, although this bias was mostly limited to basins with complex terrain. $\overline{\mathrm{ET}}_{\mathrm{EB}}^{\mathrm{NOAH}}$ showed evidence of some systemic underestimation of annual ET across the entire CONUS region, while the mean of $\overline{\mathrm{ET}_{\mathrm{EB}}^{\mathrm{MOD} 16}}$ was very close to the mean of $\overline{\mathrm{ET}_{\mathrm{WB}}}$. All three $\overline{\mathrm{ET}_{\mathrm{EB}}}$ products seem capable of tracking ET climatology in the central part of the country, albeit with some underestimation from MOD16, while the three $\overline{\mathrm{ET}_{\mathrm{EB}}}$ products differed from $\overline{\mathrm{ET}_{\mathrm{WB}}}$ and each other in the eastern third of CONUS and along the West Coast, a result consistent with previous analysis (Anderson et al. 2013). Our examination of rank 
correlations between $\overline{\varepsilon_{\mathrm{NC}}}$ and watershed characteristics (Fig. 3) suggested that 1) $\overline{\mathrm{ET}_{\mathrm{EB}}^{\mathrm{ALEI}}}$ is overestimated in basins with high mean annual precipitation and complex terrain, and 2) $\mathrm{ET}_{\mathrm{EB}}^{\mathrm{MOD16}}$ is also overestimated in basins with higher mean precipitation and complex terrain, but also underestimates ET in basins with more cloud cover (\%NA retrievals from ALEXI as a proxy) and overestimates ET in basins with more energy supplied in the form of summertime vertically integrated heat flux $\overline{H_{\text {HORIZ }}}$.

Importantly, the high correlation coefficients seen between mean annual precipitation and $\overline{\varepsilon_{\mathrm{NC}}^{\mathrm{ALEI}}}$ and $\overline{\varepsilon_{\mathrm{NC}}^{\mathrm{MOD} 16}}$ were absent for $\overline{\varepsilon_{\mathrm{NC}}^{\mathrm{NOH}}}$. Since Noah has NLDAS-2 $P$ as forcing, and is of similar model formulation to MOD16, the differences between these two products may highlight regions where long-term errors in $P$ play an important role in depressing the bias term $\overline{\varepsilon_{\mathrm{NC}}^{\mathrm{NOH}}}$. Accordingly, the regions with the most prominent contrasts in bias terms

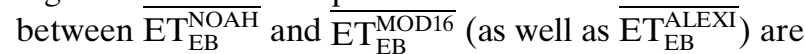
in mountainous regions of the eastern United States and Pacific Northwest, where gauge placement is expected to have an outsized role in long-term bias in gridded $P$ estimates. However, the information content of the remotely sensed inputs to MOD16 and ALEXI may be degraded in regions of complex terrain, so it is difficult to distinguish if long-term nonclosure error in complex terrain is related to the degradation of remotely sense data inputs or error in precipitation.

This analysis also confirms that at very long time scales $(10+$ years, Fig. 2) $\overline{\Delta \mathrm{TWS}}$ is a negligible part of the terrestrial water budget in most of the basins considered, reducing a potential error term in $\overline{\mathrm{ET}_{\mathrm{WB}}}$. Taken together, the results above suggest that, at least on a long-term basis, the accuracy of at least some of the $\overline{\mathrm{ET}_{\mathrm{EB}}}$ estimates are degraded, particularly in humid regions. This is consistent with previous analyses of longterm bias (Sheffield et al. 2009; Gao et al. 2010). Further, we argue that the analysis presented here points most strongly to some degradation for the Noah product, given that it shares the same precipitation forcing as and is biased downward against $\overline{\mathrm{ET}_{\mathrm{WB}}}$ - a bias that cannot be explained by known, systematic sources of precipitation error (e.g., undercatch).

Many studies have indicated that $\mathrm{ET}_{\mathrm{EB}}$ cannot be used to close annual terrestrial water budgets (Zhang et al. 2012; Zeng et al. 2014; Velpuri et al. 2013; Han et al. 2015; Liu et al. 2016). Our analysis indicates that in regions with water-limited $\mathrm{ET}$ and low interannual $\mathrm{ET}_{\mathrm{WB}}$ variability-specifically in the central United States ranging from Texas up through the high plains-all three $\mathrm{ET}_{\mathrm{EB}}$ products demonstrated hydrologic consistency with $\mathrm{ET}_{\mathrm{WB}}$. Even in these areas, however, the $\mathrm{ET}_{\mathrm{EB}}$ products were still only able to capture less than half the magnitude of scaled interannual variance estimated by $\mathrm{ET}_{\mathrm{WB}}$. Also, in many regions of the country like the eastern United States and the Pacific Northwest, no or weak consistency is seen between $\mathrm{SET}_{\mathrm{EB}}^{\prime}$ and $\mathrm{sET}_{\mathrm{WB}}^{\prime}$. In addition, the variance of unscaled $\mathrm{ET}_{\mathrm{WB}}$ is from twice to more than 10 times the variance of unscaled $\mathrm{ET}_{\mathrm{EB}}$ estimates throughout the CONUS, although this variance bias is smallest with the ALEXI product.

Clustering was seen in basin-level ${ }_{s} \varepsilon_{\mathrm{NC}}$ in certain regions and years, a phenomenon that suggests some of these errors are linked to specific climate events that contribute substantially to discrepancies between $\mathrm{ET}_{\mathrm{EB}}$ and $\mathrm{ET}_{\mathrm{WB}}$. To explore whether errors in $\mathrm{ET}_{\mathrm{WB}}$ or $\mathrm{ET}_{\mathrm{EB}}$ were the cause of clustering in nonclosure errors, we correlated ${ }_{s} \varepsilon_{\mathrm{NC}}$ with four key variables that might drive these errors in either $\mathrm{ET}_{\mathrm{WB}}(P, \Delta \mathrm{TWS})$ or $\mathrm{ET}_{\mathrm{EB}}(\% P$ as snow, and $\left.H_{\text {HORIZ }}\right)$. Results showed interesting patterns of correlation between ${ }_{s} \varepsilon_{\mathrm{NC}}$ and all of these variables, although correlations were largest and most widespread with $P$ and $\Delta$ TWS. This was despite the mismatch in resolution between the GRACE-based $\Delta$ TWS estimates and basin sizes. These results generally support the conclusions of Han et al. (2015) that uncertainties in water budget ET estimates play a large role in interannual nonclosure errors, although these conclusions should likely be modulated somewhat given the longterm biases in energy budget-based methods and potential sources of interannual errors linked to sublimation and large-scale heat advection.

Further research is needed to identify whether largescale climatic drivers of terrestrial ET, including phenomena that contribute to atmospheric coupling and the thresholds for energy-limited ET, are adequately parameterized in continental-scale energy balance models. A significant question that remains is whether the variance bias contributing to $\varepsilon_{\mathrm{NC}}$ across the CONUS is due to overestimation of interannual variability in $\mathrm{ET}_{\mathrm{WB}}$ or underestimation of interannual variability in $\mathrm{ET}_{\mathrm{EB}}$. While some of this bias is due to the interannual fluctuation in basin $\Delta$ TWS and inflated variance bias in estimates of basin $P$, it is unclear if this is the sole source. As ET is commonly assumed to have relatively low variability on an interannual basis, resolution to this question could serve to validate or challenge a critical assumption of terrestrial hydrologic models.

The modestly improved relationships seen between nonclosure errors and the higher-resolution GRACE Mascon data over the Tellus data suggest that further improvements in the resolution of $\Delta$ TWS estimates may be needed to help resolve these questions. We feel the mismatch in resolution between the $\Delta$ TWS data and basin sizes used in this study was a major limitation of the approach, despite the significant signals that were uncovered. Therefore, as new and higher-resolution GRACE products continue to be 
developed, we argue for the importance of revisiting $\mathrm{ET}_{\mathrm{WB}}$ and $\mathrm{ET}_{\mathrm{EB}}$ comparisons in future work using this data.

Acknowledgments. NLDAS-2 data used in this study, including data from the Noah LSM, were acquired as part of the mission of NASA's Earth Science Division and archived and distributed by the Goddard Earth Sciences (GES) Data and Information Services Center (DISC). GRACE land data are available at http:/grace.jpl.nasa.gov, supported by the NASA MEaSUREs Program. MOD16 ET data were acquired from the Numerical Terradynamical Simulation Group (NTSG) at the University of Montana with availability supported by NASA. Funding for this research was provided by NASA's Applied Sciences Water Resources Program (Grant NNX12AK90G).

\section{REFERENCES}

Adam, J. C., and D. P. Lettenmaier, 2003: Adjustment of global gridded precipitation for systematic bias. J. Geophys. Res., 108, 4257, https://doi.org/10.1029/2002JD002499.

Anderson, M. C., J. M. Norman, G. R. Diak, W. P. Kustas, and J. R. Mecikalski, 1997: A two-source time-integrated model for estimating surface fluxes using thermal infrared remote sensing. Remote Sens. Environ., 60, 195-216, https://doi.org/ 10.1016/S0034-4257(96)00215-5.

—_, and Coauthors, 2011: Mapping daily evapotranspiration at field to continental scales using geostationary and polar orbiting satellite imagery. Hydrol. Earth Syst. Sci., 15, 223-239, https://doi.org/10.5194/hess-15-223-2011.

, and Coauthors, 2012: Mapping daily evapotranspiration at Landsat spatial scales during the BEAREX'08 field campaign. Adv. Water Resour., 50, 162-177, https://doi.org/10.1016/ j.advwatres.2012.06.005.

, C. Hain, J. Otkin, X. Zhan, K. Mo, M. Svoboda, B. Wardlow, and A. Pimstein, 2013: An intercomparison of drought indicators based on thermal remote sensing and NLDAS-2 simulations with U.S. Drought Monitor classifications. J. Hydrometeor., 14, 1035-1056, https://doi.org/10.1175/JHM-D-12-0140.1.

Anderson, R. G., M.-H. Lo, S. Swenson, J. S. Famiglietti, Q. Tang, T. H. Skaggs, Y. H. Lin, and R. J. Wu, 2015: Using satellite-based estimates of evapotranspiration and groundwater changes to determine anthropogenic water fluxes in land surface models. Geosci. Model Dev., 8, 3021-3031, https://doi.org/10.5194/gmd-8-3021-2015.

Bivand, R., and D. Yu, 2017: Spgwr: Geographically weighted regression, version $0.6-31 / \mathrm{r} 1743$. $\mathrm{R}$ package, https://cran. r-project.org/web/packages/spgwr/index.html.

Brunsdon, C., S. Fotheringham, and M. Charlton, 1998: Geographically weighted regression. Statistician, 47 (3), 431-443.

Cai, X., Z. L. Yang, C. H. David, G. Y. Niu, and M. Rodell, 2014: Hydrological evaluation of the Noah-MP land surface model for the Mississippi River Basin. J. Geophys. Res. Atmos., 119, 23-38, https://doi.org/10.1002/2013JD020792.

Chen, F., and Coauthors, 1996: Modeling of land-surface evaporation by four schemes and comparison with FIFE observations. J. Geophys. Res., 101, 7251-7268, https://doi.org/10.1029/95JD02165.

Choi, M., W. P. Kustas, M. C. Anderson, R. G. Allen, F. Li, and J. H. Kjaersgaard, 2009: An intercomparison of three remote sensing-based surface energy balance algorithms over a corn and soybean production region (Iowa, US) during SMACEX.
Agric. For. Meteor., 149, 2082-2097, https://doi.org/10.1016/ j.agrformet.2009.07.002.

Cleugh, H. A., R. Leuning, Q. Mu, and S. W. Running, 2007: Regional evaporation estimates from flux tower and MODIS satellite data. Remote Sens. Environ., 106, 285-304, https://doi.org/ 10.1016/j.rse.2006.07.007.

Dee, D. P., and Coauthors, 2011: The ERA-Interim reanalysis: Configuration and performance of the data assimilation system. Quart. J. Roy. Meteor. Soc., 137, 553-597, https://doi.org/10.1002/qj.828.

Döll, P., H. Hoffmann-Dobrev, F. T. Portmann, S. Siebert, A. Eicker, M. Rodell, G. Strassberg, and B. R. Scanlon, 2012: Impact of water withdrawals from groundwater and surface water on continental water storage variations. J. Geodyn., 59-60, 143-156, https://doi.org/10.1016/j.jog.2011.05.001.

Falcone, J. A., D. M. Carlisle, D. M. Wolock, and M. R. Meador, 2010: GAGES: A stream gage database for evaluating natural and altered flow conditions in the conterminous United States. Ecology, 91, 621-621, https://doi.org/10.1890/09-0889.1.

Ferguson, C. R., J. Sheffield, E. F. Wood, and H. Gao, 2010: Quantifying uncertainty in a remote sensing-based estimate of evapotranspiration over continental USA. Int. J. Remote Sens., 31, 3821-3865, https://doi.org/10.1080/ 01431161.2010 .483490$.

French, A. N., and Coauthors, 2005: Surface energy fluxes with the Advanced Spaceborne Thermal Emission and Reflection radiometer (ASTER) at the Iowa 2002 SMACEX site (USA). Remote Sens. Environ., 99, 55-65, https://doi.org/10.1016/j.rse.2005.05.015.

Gao, H., Q. Tang, C. R. Ferguson, E. F. Wood, and D. P. Lettenmaier, 2010: Estimating the water budget of major US river basins via remote sensing. Int. J. Remote Sens., 31, 3955-3978, https://doi.org/10.1080/01431161.2010.483488.

Glenn, E. P., and Coauthors, 2011: Actual evapotranspiration estimation by ground and remote sensing methods: The Australian experience. Hydrol. Processes, 25, 4103-4116, https://doi.org/10.1002/hyp.8391.

Haddeland, I., and Coauthors, 2011: Multimodel estimate of the global terrestrial water balance: Setup and first results. J. Hydrometeor., 12, 869-884, https://doi.org/10.1175/2011JHM1324.1.

Hain, C. R., W. T. Crow, M. C. Anderson, and M. T. Yilmaz, 2015: Diagnosing neglected soil moisture source-sink processes via a thermal infrared-based two-source energy balance model. J. Hydrometeor., 16, 1070-1086, https://doi.org/10.1175/ JHM-D-14-0017.1.

Han, E., W. T. Crow, C. R. Hain, and M. C. Anderson, 2015: On the use of a water balance to evaluate interannual terrestrial ET variability. J. Hydrometeor., 16, 1102-1108, https://doi.org/ 10.1175/JHM-D-14-0175.1.

Hijmans, R. J., and J. van Etten, 2014: Raster: Geographic data analysis and modeling, version 2. R package, https://cran.r-project.org/web/ packages/raster/index.html.

Jiménez, C., and Coauthors, 2011: Global intercomparison of 12 land surface heat flux estimates. J. Geophys. Res., 116, D02102, https://doi.org/10.1029/2010JD014545.

Jung, M., M. Reichstein, and A. Bondeau, 2009: Towards global empirical upscaling of FLUXNET eddy covariance observations: Validation of a model tree ensemble approach using a biosphere model. Biogeosciences, 6, 2001-2013.

Kalma, J. D., T. R. McVicar, and M. F. McCabe, 2008: Estimating land surface evaporation: A review of methods using remotely sensed surface temperature data. Surv. Geophys., 29, 421-469, https://doi.org/10.1007/s10712-008-9037-z.

Kustas, W. P., and Coauthors, 2012: Evaluating the two-source energy balance model using local thermal and surface flux observations 
in a strongly advective irrigated agricultural area. $A d v$. Water Resour., 50, 120-133, https://doi.org/10.1016/j.advwatres.2012.07.005.

Landerer, F. W., and S. C. Swenson, 2012: Accuracy of scaled GRACE terrestrial water storage estimates. Water Resour. Res., 48, W04531, https://doi.org/10.1029/2011WR011453.

Li, Z. L., R. Tang, Z. Wan, Y. Bi, C. Zhou, B. Tang, G. Yan, and X. Zhang, 2009: A review of current methodologies for regional evapotranspiration estimation from remotely sensed data. Sensors, 9, 3801-3853, https://doi.org/10.3390/s90503801.

Liu, W., L. Wang, J. Zhou, Y. Li, F. Sun, G. Fu, X. Li, and Y.-F. Sang, 2016: A worldwide evaluation of basin-scale evapotranspiration estimates against the water balance method. J. Hydrol., 538, 82-95, https://doi.org/10.1016/j.jhydrol.2016.04.006.

Mu, Q., F. A. Heinsch, M. Zhao, and S. W. Running, 2007: Development of a global evapotranspiration algorithm based on MODIS and global meteorology data. Remote Sens. Environ., 111, 519-536, https://doi.org/10.1016/j.rse.2007.04.015.

_, M. Zhao, and S. W. Running, 2011: Improvements to a MODIS global terrestrial evapotranspiration algorithm. Remote Sens. Environ., 115, 1781-1800, https://doi.org/10.1016/j.rse.2011.02.019.

Newman, A. J., and Coauthors, 2015: Development of a large-sample watershed-scale hydrometeorological data set for the contiguous USA: Data set characteristics and assessment of regional variability in hydrologic model performance. Hydrol. Earth Syst. Sci., 19, 209-223, https://doi.org/10.5194/hess-19-209-2015.

Pan, M., and Coauthors, 2003: Snow process modeling in the North American Land Data Assimilation System (NLDAS): 2. Evaluation of model simulated snow water equivalent. J. Geophys. Res., 108, 8850, https://doi.org/10.1029/2003JD003994.

Pervez, M. S., and J. F. Brown, 2010: Mapping irrigated lands at 250-m scale by merging MODIS data and national agricultural statistics. Remote Sens., 2, 2388-2412, https://doi.org/10.3390/rs2102388.

Peters-Lidard, C. D., S. V. Kumar, D. M. Mocko, and Y. Tian, 2011: Estimating evapotranspiration with land data assimilation systems. Hydrol. Processes, 25, 3979-3992, https://doi.org/10.1002/hyp.8387.

Pinker, R. T., and Coauthors, 2003: Surface radiation budgets in support of the GEWEX Continental-Scale International Project (GCIP) and the GEWEX Americas Prediction Project (GAPP), including the North American Land Data Assimilation System (NLDAS) project. J. Geophys. Res., 108, 8844, https://doi.org/10.1029/2002JD003301.

Prat, O. P., and B. R. Nelson, 2015: Evaluation of precipitation estimates over CONUS derived from satellite, radar, and rain gauge data sets at daily to annual scales (2002-2012). Hydrol. Earth Syst. Sci., 19, 2037-2056, https://doi.org/10.5194/hess-19-2037-2015.

Rienecker, M. M., and Coauthors, 2011: MERRA: NASA's modern-era retrospective analysis for research and applications. J. Climate, 24, 3624-3648, https://doi.org/10.1175/JCLI-D-11-00015.1.

Rodell, M., and J. S. Famiglietti, 2001: An analysis of terrestrial water storage variations in Illinois with implications for the Gravity Recovery and Climate Experiment (GRACE). Water Resour. Res., 37, 1327-1339, https://doi.org/10.1029/2000WR900306.

,-- J. Chen, S. I. Seneviratne, P. Viterbo, S. Holl, and C. R. Wilson, 2004: Basin scale estimates of evapotranspiration using GRACE and other observations. Geophys. Res. Lett., 31, L20504, https://doi.org/10.1029/2004GL020873.

Sahoo, A. K., M. Pan, T. J. Troy, R. K. Vinukollu, J. Sheffield, and E. F. Wood, 2011: Reconciling the global terrestrial water budget using satellite remote sensing. Remote Sens. Environ., 115, 1850-1865, https://doi.org/10.1016/j.rse.2011.03.009.

Save, H., S. Bettadpur, and B. D. Tapley, 2016: High resolution CSR GRACE RL05 mascons. J. Geophys. Res. Solid Earth, 121, 7547-7569, https://doi.org/10.1002/2016JB013007.
Sheffield, J., C. R. Ferguson, T. J. Troy, E. F. Wood, and M. F. McCabe, 2009: Closing the terrestrial water budget from satellite remote sensing. Geophys. Res. Lett., 36, L07403, https:// doi.org/10.1029/2009GL037338.

Shiklomanov, I. A., 2000: Appraisal and assessment of world water resources. Water Int., 25, 11-32, https://doi.org/10.1080/ 02508060008686794.

Swenson, S. C., 2012: GRACE monthly land water mass grids NETCDF release 5.0. PO.DAAC, accessed 10 May 2017, https://doi.org/10.5067/TELND-NC005.

Trenberth, K. E., J. T. Fasullo, and J. Kiehl, 2009: Earth's global energy budget. Bull. Amer. Meteor. Soc., 90, 311-323, https:// doi.org/10.1175/2008BAMS2634.1.

Twine, T. E., C. J. Kucharik, and J. A. Foley, 2004: Effects of land cover change on the energy and water balance of the Mississippi River basin. J. Hydrometeor., 5, 640-655, https://doi.org/ 10.1175/1525-7541(2004)005<0640:EOLCCO > 2.0.CO;2.

Velpuri, N. M., G. B. Senay, R. K. Singh, S. Bohms, and J. P. Verdin, 2013: A comprehensive evaluation of two MODIS evapotranspiration products over the conterminous United States: Using point and gridded FLUXNET and water balance ET. Remote Sens. Environ., 139, 35-49, https://doi.org/10.1016/j.rse.2013.07.013.

Vinukollu, R. K., R. Meynadier, J. Sheffield, and E. F. Wood, 2011: Multi-model, multi-sensor estimates of global evapotranspiration: climatology, uncertainties and trends. Hydrol. Processes, 25, 3993-4010, https://doi.org/10.1002/hyp.8393.

Wang, S., and Coauthors, 2015: Comparing evapotranspiration from Eddy covariance measurements, water budgets, remote sensing, and land surface models over Canada. J. Hydrometeor., 16, 1540-1560, https://doi.org/10.1175/JHM-D-14-0189.1.

Wheeler, D., and M. Tiefelsdorf, 2005: Multicollinearity and correlation among local regression coefficients in geographically weighted regression. J. Geogr. Syst., 7, 161-187, https://doi.org/ 10.1007/s10109-005-0155-6.

Wiese, D. N., 2015: GRACE monthly global water mass grids NETCDF release 5.0, version 5.0. PO.DAAC, accessed 18 March 2017, https://doi.org/10.5067/TEMSC-OCL05.

Xia, Y., and Coauthors, 2012: Continental-scale water and energy flux analysis and validation for the North American Land Data Assimilation System project phase 2 (NLDAS-2): 1. Intercomparison and application of model products. J. Geophys. Res., 117, D03109, https://doi.org/10.1029/2011JD016048.

, M. T. Hobbins, Q. Mu, and M. B. Ek, 2015: Evaluation of NLDAS-2 evapotranspiration against tower flux site observations. Hydrol. Processes, 29, 1757-1771, https://doi.org/10.1002/hyp.10299.

Yang, D., D. Kane, Z. Zhang, D. Legates, and B. Goodison, 2005: Bias corrections of long-term (1973-2004) daily precipitation data over the northern regions. Geophys. Res. Lett., 32, L19501, https://doi.org/10.1029/2005GL024057.

Zeng, Z., S. Piao, X. Lin, G. Yin, S. Peng, P. Ciais, and R. B. Myneni, 2012: Global evapotranspiration over the past three decades: Estimation based on the water balance equation combined with empirical models. Environ. Res. Lett., 7, 014026, https:// doi.org/10.1088/1748-9326/7/1/014026.

— - T. Wang, F. Zhou, P. Ciais, J. Mao, X. Shi, and S. Piao, 2014: A worldwide analysis of spatiotemporal changes in water balance-based evapotranspiration from 1982 to 2009 . J. Geophys. Res. Atmos., 119, 1186-1202, https://doi.org/ 10.1002/2013JD020941.

Zhang, Y., and Coauthors, 2012: Decadal trends in evaporation from global energy and water balances. J. Hydrometeor., 13, 379-391, https://doi.org/10.1175/JHM-D-11-012.1. 